\title{
A estagnação da produtividade do trabalho na indústria brasileira nos anos 1996-2007: análise nacional, regional e setorial
}

Edileuza Galeano Doutora em Economia pela Universidade Federal Fluminense-UFF

Carmen Feijó Professora Associada do Departamento de Economia da Universidade Federal Fluminense - UFF, Pesquisadora Nível I do CNPq, $\mathrm{PhD}$ pelo University College London, Inglaterra

\begin{abstract}
Palauras-chave
indústria, produtividade do trabalho, análise regional $\mathrm{e}$ setorial, shift-share.
\end{abstract}

Classificação JEL R11, R12, O14.

\section{Keywords \\ industry, labor productivity, regional and sectorial analysis, shift-share}

JEL Classification $R 11, R 12$, O14.

\section{Resumo}

O artigo apresenta uma análise regional e setorial da produtividade do trabalho na indústria nos anos 1996-2007 a partir dos dados da PIA-IBGE utilizando o método shift-share. Foi feita uma ponderaçáo da produtividade do trabalho de cada setor e regiáo pela sua respectiva participação no emprego nacional. Os resultados dos cálculos das componentes de crescimento da produtividade do trabalho mostraram que, na maioria dos setores e regióes, a componente de crescimento estrutural modificada tem baixa relação com o crescimento da produtividade do trabalho. Concluiu-se que o crescimento da produtividade nos setores e regióes foi mais em razáo da própria competitividade regional do que das mudanças na estrutura produtiva. Verificou-se também que o crescimento das regióes menos desenvolvidas foi insuficiente para compensar o decréscimo na regiáo Sudeste, náo havendo incremento na produtividade do trabalho em nível nacional..

\section{Abstract}

The paper presents a regional and sectorial analysis of labor productivity in industry in the years 1996-2007 from the data of PIAIBGE using the shift-share method. Labor productivity was weighted in each sector and region for their respective participation in national employment. The results of calculations of the components of growth in labor productivity showed that in most sectors and regions, the modified structural component of growth has a low relationship with the growth of labor productivity. It was concluded that productivity growth in sectors and regions was due more to regional competitiveness than to the changes in the production structure. It was also found that growth of less developed regions was insufficient to compensate for the reduction in the Southeast region and therefore there was no increase in labor productivity at the national level. 


\section{1_Introdução}

A relação entre a estrutura econômica de um país e a evolução da produtividade ocupa espaço privilegiado em modelos de crescimento com ênfase no papel da demanda agregada. Esses modelos sugerem que os países que se especializam em indústrias tecnologicamente avançadas alcançarão altas taxas de crescimento em comparação a outros países. Fagerberg (2000), por exemplo, avalia o impacto da especialização e de mudanças estruturais no crescimento da produtividade em 24 setores da indústria de transformação de 39 países, no período de 1973 e 1990. Mostra que, embora a mudança estrutural, em média, não tenha sido favorável ao crescimento da produtividade, países que conseguiram aumentar sua presença nas indústrias mais tecnologicamente avançadas tiveram maior crescimento da produtividade. A análise da relação entre mudança estrutural e crescimento da produtividade foi feita utilizando-se a metodologia shift-share. ${ }^{1}$ Empregando-se a mesma metodologia, Rocha (2007) mensura a contribuição da mudança estrutural para o incremento da produtividade do trabalho na indústria no Brasil, no período de 1970 a 2001.

O objetivo deste artigo é analisar o comportamento da produtividade do trabalho nas regióes do Brasil por meio do método de decomposição de taxa de crescimento, shift-share. Entre as várias versóes desse método, optou-se pela de Stilwell (1969), que considera a possibilidade de captar mudança na estrutura setorial das atividades entre intervalos de tempo.

O propósito do estudo é o de buscar sinais da relevância das componentes regional e estrutural na promoção do dinamismo da produtividade em nível de setores de atividades e regióes no período de 1996-2007. Será feita uma verificação, mediante as componentes global, estrutural e regional, da importância das regióes e dos setores na evoluçáo da produtividade do trabalho para avaliar o impacto da especialização e de mudanças estruturais no crescimento da produtividade na indústria extrativa e de transformação nas regióes do Brasil. Serão utilizados dados da indústria extrativa e dos 23 setores de atividade da indústria de transformação, usando-se a Classificação Nacional de Atividades Econômicas (CNAE) para os anos de 1996 e 2007, divulgados pela Pesquisa Industrial Anual (PIA).

A seção 2 faz uma breve discussão sobre a configuração regional recente da indústria no Brasil. A seção 3 mostra como o crescimento da produtividade difere entre os setores e as regiôes. A seção 4 apresenta a metodologia a ser empregada e as taxas de crescimento da pro-
${ }^{1}$ Fagerberg mostra também que parece haver relação entre o grau de inovaçáo tecnológica, a sofisticação da indústria e o crescimento da produtividade, embora haja provavelmente também outros fatores em jogo. 
${ }^{2}$ A literatura recente que discute os determinantes da desconcentração conta com as contribuições de Cano (1997), Diniz (1993), Guimarães Neto (1997), Pacheco (1998, 1999), Sabóia, (2000), entre outros. dutividade do trabalho dos setores e das regiōes calculadas valendo-se da ponderação pela sua participação no emprego nacional. A seção 5 mostra os resultados da decomposição da taxa de crescimento da produtividade do trabalho em três componentes, conforme a metodologia apresentada; por fim, têm-se as considerações finais.

\section{2_Configuração regional recente da indústria no Brasil}

Na década de 1990, período marcado pela abertura econômica, estabilidade de preços e privatizaçóes, acentuaram-se mudanças na configuração regional da indústria, que caminhou na direçâo de mais desconcentração. ${ }^{2}$ Esse processo de desconcentração já teria se iniciado nas décadas anteriores, conforme mostrado por Diniz (1993). Para explicar o início do processo de desconcentração, esse autor enfatiza as deseconomias de aglomeração em algumas áreas mais industrializadas e as novas formas de organização da grande empresa. Descreve o chamado "desenvolvimento poligonal", que é o resultado de um conjunto de forças, sendo as mais representativas as deseconomias de aglomeração na Região Metropolitana de São Paulo; a criação de economias de aglomeração em vários outros centros urbanos e regiōes; e a ação do Estado mediante investimentos, incentivos fiscais e investimento em infraestrutura.

A desconcentração geográfica da produçáo conta ainda com a busca de recursos naturais, estimulando a abertura de novas regióes para o desenvolvimento econômico. A grande concentração espacial e social da renda, no entanto, e o consequente poder de compra retêm o crescimento em regióes com maior base econômica. Conforme Diniz (1993), um limitado número de novos polos de crescimento ou regióes teria capturado a maior parte das novas atividades econômicas, o que teria levado a uma desconcentração concentrada. Mesmo assim, conclui que, embora a produção se encontre mais dispersa, o poder e as decisóes centrais, o efeito propulsor e o ambiente inovador continuam concentrados na grande metrópole paulista. De acordo com o autor, o polígono de aglomeraçáo industrial ficou restrito aos chamados "eixos de desconcentração", mais concentrados no Sudeste e Sul.

O processo de desconcentração requer a existência de novas economias de aglomeração em outras regiốes, tais como o crescimento da renda e da população em outros locais; a expansão do mercado; a difusão do conhecimento; a expansão da infraestrutura e a criação de Distri- 
tos Industriais. De acordo com Azevedo e Junior (1999), a forte concentraçáo regional da renda no Brasil está associada a um desenvolvimento industrial desigual, fruto em parte do processo de substituição das importaçóes que se concentrou na região Sudeste, especialmente em São Paulo e na sua Região Metropolitana. Os planos de desenvolvimento que foram implementados a partir dos anos 1960 tinham o objetivo de reverter o efeito da chamada "polarização" ou concentração. As políticas institucionais foram de grande importância para o crescimento da participação das regióes menos desenvolvidas na produçáo industrial. ${ }^{3}$ A ausência de uma política ativa de incentivos para essas regióes nos últimos anos tem desfavorecido o desenvolvimento industrial nessas. Como destacou Pacheco (1999), à medida que os programas de investimento patrocinados pelo Estado vão maturando e não são substituídos por políticas ativas, os processos de desconcentração diminuem sua abrangência, o que é visível, por exemplo, na economia nordestina, que passa a ser cada vez menos beneficiária no processo de desconcentração.

Com as mudanças ocorridas na configuração econômica a partir dos anos 1990, o novo ideário de desenvolvimento passa a ser focado na competiçáo dos mercados em escalas local, nacional e mundial (Lemos, et al., 2003). Essa ênfase tende a contribuir para o fortalecimento dos centros hegemônicos, o enfraquecimento dos espaços periféricos e o abandono de políticas voltadas à integração nacional. Os investimentos em geral inclinam-se a se direcionar às estruturas já consolidadas como nas rotas de exportação de produtos primários em direção a portos de escoamento (Ruiz; Domingues, 2008).

De acordo com uma pesquisa do IPEA publicada em De Negri e Almeida (2010), o Estado voltou, na década atual, a ter papel mais ativo na promoção do crescimento industrial e no desenvolvimento econômico, e retomaram-se as políticas industriais com o objetivo de promover setores econômicos e incen-

\author{
${ }^{3}$ No caso da regiáo Nordeste, \\ conforme Galindo (1997), \\ a integração teve impacto \\ seletivo, já que se exportam \\ bens intermediários para a \\ indústria da região Sudeste, \\ o que tornou mais intenso o \\ fluxo de mercadorias (bens \\ de consumo final) do Sudeste \\ para o Nordeste, o qual \\ aumentou a importação de \\ produtos industrializados
}

na região Sudeste. Existe uma divisão inter-regional do trabalho onde a região Nordeste desempenha papel subsidiário e funcional. Esses aspectos, somados a outros de ordem mais geral, resultaram em queda da produtividade regional e em atraso tecnológico dessa região, verificada nas décadas seguintes a de 1980 . 
tivar inovação. ${ }^{4}$ Já Oliveira e Magalhães (2010), também do IPEA, fazem uma avaliação de compatibilidade entre a Política Nacional de Desenvolvimento Regional (PNDR) e o Programa de Aceleração do Crescimento (PAC) e revelam ausência de coordenação e congruência entre as açóes e os investimentos previstos no programa e nas diretrizes dessa política. Já a análise da distribuição regional da indústria não apenas confirmou aumento da distribuição da indústria no território brasileiro, mas também revelou que as microrregióes que ofertaram mais empregos em setores industriais avançados continuaram a ser justamente as que já possuíam base industrial consolidada ou vizinhas industrializadas. Isso demonstra

\footnotetext{
${ }^{4}$ Conforme De Negri e

Almeida (2010), as políticas podem ser classificadas em quatro tipos diferentes: i) políticas voltadas para "completar" cadeias produtivas já existentes, como os incentivos concedidos à indústria automobilística; ii) políticas voltadas para o desenvolvimento de setores modernos com impacto em todo o sistema econômico: indústrias eletrônica e de informática; iii) políticas de controle e regulação de setores de elevada concentração
}

(energia, telecomunicação, petróleo e gás); e iv) políticas voltadas para o fortalecimento de pequenas e de médias empresas em clusters, mais conhecidos no Brasil como "políticas de fomento" a Arranjos Produtivos Locais (APLs).

${ }^{5} \mathrm{~A}$ atividade de P\&D é muito onerosa, por isso as regiôes que náo conseguem inovar, devem aproveitar a tecnologia criada pelas regióes mais desenvolvidas como resultado da difusão (Romer, 1993a, 1993b). que os incentivos fiscais não conseguiram suplantar os fatores locacionais, como mão de obra qualificada e acesso a fornecedores e ao mercado consumidor.

A elevada concentraçáo econômica das atividades nas regióes Sudeste e Sul ainda é um traço característico da economia brasileira. Considerando a indústria de transformação, setor que por suas características é o de maior dinamismo em termos de crescimento, apesar da tendência de queda de sua participação no PIB, a presença da regiáo Sudeste no total do VTI nos anos 1990 e nos anos 2000 continuou acima de $60 \%$.

As taxas de crescimento econômico nos anos recentes na região Sudeste têm sido mais baixas que as das demais regióes. De um lado, isso permite que as desigualdades regionais não aumentem, uma vez que as regióes menos desenvolvidas continuam a se expandir em ritmo superior. De outro lado, porém, a regiáo $\mathrm{Su}$ deste, crescendo menos, perde a capacidade de liderança sobre as regióes menos desenvolvidas (Monteiro Neto, 2006). Isso provoca efeitos de retardo também sobre as regióes menos desenvolvidas, principalmente quando se trata de $\mathrm{P} \& \mathrm{D},{ }^{5}$ cujo investimento é alto, e os benefícios podem demorar a apresentar resultados econômicos. De fato, o processo de desconcentração industrial não veio acom- 
panhado de aumento de produtividade do setor industrial. ${ }^{6}$ Rocha (2007) mostra, utilizando dados da PIA, que, a partir de meados da década de 1990, houve redução no ritmo de crescimento da produtividade do trabalho na indústria do Brasil, sendo a taxa média de crescimento para o período de 1996 a 2001 próxima de zero (0,49\% a.a.). Conforme Nassif (2008), após 1991 a indústria mostrou incrementos na produtividade do trabalho. Já o comportamento da produção física e principalmente do emprego industrial no período foi mais volátil. Em média, prevaleceu uma queda no emprego industrial, a partir dos anos 1990. Na primeira metade da década de 1990, as taxas de crescimento médias anuais da produtividade do trabalho eram positivas, porém elas não se sustentaram após 1999. Aliada ao forte declínio do investimento bruto da economia, a indústria de transformação não foi capaz de recuperar os níveis de participação no PIB que prevaleceram até meados da década anterior. A partir da segunda metade da década de 1990, houve tendência de retração dos índices de produtividade do trabalho, sobretudo no período posterior a 1999 , quando o indicador passou a apresentar taxas negativas de variação. Nassif mostra que, no período 1996-2004, a variação média anual da produtividade do traba- lho da indústria de transformação brasileira foi da ordem de $-2,6 \%$. Um sinal de reversão dessa tendência só ocorre em 2004, quando a produtividade do trabalho registrou acréscimo de $1 \%$. A próxima seção mostra o comportamento da produtividade do trabalho na indústria brasileira, no período de 1996 a 2007.

\section{Produtividade do trabalho na indústria}

Além das mudanças advindas do processo de desconcentração industrial, conforme apresentado na literatura, as transformações na estrutura produtiva da indústria provocadas pela abertura econômica alteraram de forma mais significativa sua participação no comércio internacional nos anos 1990. Dada a estrutura da economia brasileira, com vantagens comparativas em setores intensivos em recursos naturais, o recente aumento no comércio internacional apresenta reflexos sobre a composição do produto da indústria, levando a um aumento na especialização na produção de commodities industriais (Lamonica; Feijó, 2011).

A nova teoria de crescimento endógeno estabelece que políticas de abertura comercial podem exercer efeito positivo sobre o crescimento da produtividade

\footnotetext{
${ }^{6}$ Vale observar que vários autores identificaram ganhos significativos de produtividade na indústria de transformação no Brasil, atribuídos em grande medida à abertura no início da década de 1990 (Feijó; Carvalho, 1999, 2002; Bonelli; Fonseca 1998, entre outros). No entanto, passado o impacto inicial da abertura econômica sobre a estrutura de custos da indústria e a modernizaçáo do parque manufatureiro, os ganhos de produtividade se reduziram, tendo em vista que os investimentos produtivos não recuperaram de forma significativa até, pelo menos, meados dos anos 2000.
} 
Tabela 1_Produtividade média do trabalho na indústria a preços de 1996 (R\$ mil) e taxa de crescimento de 1996 a 2007 , no Brasil

\begin{tabular}{l|r|r|r|r|r|r|r|r|r|r|r|r|r|r|r|r|r|r|}
\hline Variável/Ano & $\mathbf{1 9 9 6}$ & $\mathbf{1 9 9 7}$ & $\mathbf{1 9 9 8}$ & $\mathbf{1 9 9 9}$ & $\mathbf{2 0 0 0}$ & $\mathbf{2 0 0 1}$ & $\mathbf{2 0 0 2}$ & $\mathbf{2 0 0 3}$ & $\mathbf{2 0 0 4}$ & $\mathbf{2 0 0 5}$ & $\mathbf{2 0 0 6}$ & $\mathbf{2 0 0 7}$ & Média \\
\hline Prod. trabalho $(\mathrm{R} \$ \mathrm{mil})$ & 31,76 & 34,15 & 34,55 & 35,16 & 34,56 & 35,6 & 35,13 & 31,71 & 31,17 & 30,68 & 31,55 & 31,56 & 33,13 \\
\hline Taxa de crescimento \% & & 7,53 & 1,17 & 1,77 & $-1,71$ & 3,00 & $-1,29$ & $-9,73$ & $-1,70$ & $-1,57$ & 2,82 & 0,03 & 0,03
\end{tabular}

Fonte: Elaboração dos autores, com base nos dados do IBGE e da FGV, 2011.

(Romer, 1993a, 1993b), por meio da indução de mudanças tecnológicas. No entanto, Grossman e Helpman (1990) observaram que o aumento da competição subsequente à abertura de uma economia pode vir a desencorajar o processo de de inovação pela expectitiva de redução dos lucros. ${ }^{7}$ Desse modo, somente países ou regiōes com vantagens comparativas nos setores intensivos em pesquisa e tecnologia se beneficiariam com a abertura econômica. Concluem que é ambíguo o efeito da abertura sobre a economia, se a abertura não provocar mudança estrutu- ral na direção da produção de bens com mais conteúdo tecnológico.

Uma variável importante para sinalizar mudanças na estrutura produtiva é a produtividade do trabalho. Para avaliar a evolução da produtividade regional do trabalho com informaçóes da Pesquisa Industrial Anual do IBGE, o conceito de produtividade do trabalho utilizado é "produtividade-homem", ou seja, o valor da transformação industrial dividido pelo estoque de trabalhadores em 31/12.

A Tabela 1 mostra o nível real da produtividade do trabalho e as suas taxas
${ }^{7}$ Conforme Moreira (1999), nos primeiros anos do plano de estabilização, o câmbio supervalorizado incentivava as importaçôes e prejudicava as exportações. Houve aumento significativo do coeficiente de importação da indústria de transformação brasileira, principalmente nos setores mais intensivos em tecnologia. Carvalho Jr. e Ruiz (2008) destacam que as principais alterações apontadas na maioria dos estudos sobre a indústria brasileira, após a abertura, são a redução nas taxas de lucro, o aumento na concentração industrial via fusões e aquisições, o aumento da participação do capital estrangeiro e da produtividade. Esta última está associada à modernização das firmas e ao aumento da con $\neg$ corrência de bens importados. Houve mudanças na estrutura produtiva, com alguns setores se modernizando e outros diminuindo sua importância no decorrer do processo de ajuste às novas condiçóes de mercado. Houve expressivo aumento na produtividade do trabalho para aqueles setores que se modernizaram, e isso expôs ainda mais as diferenças de produtividade entre os setores. Conforme Bonelli (2002), parte do aumento da produtividade pode ser buscada no desaparecimento das empresas mais ineficientes, uma vez que, até então, estavam garantidas por um regime comercial de alta proteção. 
Tabela 2_Participação \% do emprego, nível de produtividade (R\$ mil a preços de 1996) e variação \% da produtividade do trabalho de 2007 em relação a 1996, e a média de crescimento dos 11 anos (1996 a 2007)

\begin{tabular}{|c|c|c|c|c|c|c|}
\hline Classificação Nacional de Atividades Econômicas & $\begin{array}{l}\text { Participac } \\
1996\end{array}$ & $\begin{array}{l}0 \% \text { (PO) } \\
2007\end{array}$ & $\begin{array}{l}\text { Produtivid } \\
1996\end{array}$ & $\begin{array}{l}\text { ade R\$ mil } \\
2007\end{array}$ & $\begin{array}{l}\text { Crescimento } \\
2007 / 1996\end{array}$ & $\begin{array}{l}\text { Crescimento } \\
\text { Médio }\end{array}$ \\
\hline C Indústrias extrativas & 2,28 & 2,32 & 47,53 & 77,45 & 62,94 & 5,18 \\
\hline D Indústrias de transformação & 97,72 & 97,68 & 31,39 & 30,47 & $-2,93$ & $-0,18$ \\
\hline Baixa tecnologia & 51,96 & 50,93 & 23,52 & 22,01 & $-6,42$ & $-0,45$ \\
\hline 15 Fabricação de produtos alimentícios e bebidas & 17,86 & 19,72 & 31,03 & 25,51 & $-17,8$ & $-1,48$ \\
\hline 16 Fabricação de produtos do fumo & 0,43 & 0,25 & 82,09 & 138,12 & 68,26 & 7,88 \\
\hline 17 Fabricação de produtos têxteis & 5,77 & 4,45 & 18,44 & 17,44 & $-5,42$ & $-0,29$ \\
\hline 18 Confecção de artigos do vestuário e acessórios & 7,46 & 7,65 & 9,68 & 17,22 & 77,95 & 5,77 \\
\hline $\begin{array}{l}19 \text { Preparação de couros e fabricação de artefatos de couro, artigos de } \\
\text { viagem e calçados }\end{array}$ & 5,39 & 5,64 & 13,12 & 12,68 & $-3,32$ & $-0,16$ \\
\hline 20 Fabricação de produtos de madeira & 3,37 & 3,14 & 10,63 & 12,48 & 17,36 & 2,01 \\
\hline 21 Fabricaçáo de celulose, papel e produtos de papel & 2,87 & 2,36 & 41,55 & 45,99 & 10,69 & 1,22 \\
\hline 22 Edição, impressão e reprodução de gravações & 3,84 & 2,98 & 40,71 & 29,41 & $-27,77$ & $-2,28$ \\
\hline 36 Fabricação de móveis e indústrias diversas & 4,91 & 4,45 & 14,39 & 14,37 & $-0,12$ & 0,11 \\
\hline 37 Reciclagem & 0,06 & 0,28 & 21,56 & 11,07 & $-48,64$ & $-3,95$ \\
\hline Média baixa tecnologia & 21,54 & 21,68 & 33,16 & 28,91 & $-12,81$ & $-1,13$ \\
\hline $\begin{array}{l}23 \text { Fabricação de coque, refino de petróleo, elaboração de } \\
\text { combustíveis nucleares e produçáo de álcool }\end{array}$ & 2,57 & 2,11 & 70,53 & 78,79 & 11,72 & 4,09 \\
\hline 25 Fabricação de artigos de borracha e plástico & 4,87 & 5,14 & 26,52 & 18,35 & $-30,81$ & $-3,1$ \\
\hline 26 Fabricação de produtos de minerais não metálicos & 5,03 & 4,93 & 21,69 & 21,31 & $-1,72$ & $-0,09$ \\
\hline 27 Metalurgia básica & 3,48 & 3,12 & 49,39 & 51,97 & 5,24 & 0,93 \\
\hline $\begin{array}{l}28 \text { Fabricação de produtos de metal } \\
\text { - exceto máquinas e equipamentos }\end{array}$ & 5,60 & 6,39 & 22,03 & 15,5 & $-29,66$ & $-2,86$ \\
\hline Média alta tecnologia & 22,29 & 23,27 & 45,10 & 42,12 & $-6,61$ & $-0,46$ \\
\hline 24 Fabricação de produtos químicos & 5,64 & 5,04 & 69,93 & 56,85 & $-18,7$ & $-1,7$ \\
\hline 29 Fabricação de máquinas e equipamentos & 6,42 & 6,92 & 34,26 & 28,12 & $-17,9$ & $-1,48$ \\
\hline 31 Fabricação de máquinas, aparelhos e material elétrico & 2,84 & 2,93 & 30,69 & 22,21 & $-27,65$ & $-2,18$ \\
\hline $\begin{array}{l}33 \text { Fabricação de equipamentos de instrumentação médico- } \\
\text { hospitalares, instrumentos de precisão e ópticos, equipamentos para } \\
\text { automação industrial, cronômetros e relógios }\end{array}$ & 0,97 & 1,09 & 27,27 & 26,04 & $-4,52$ & $-0,1$ \\
\hline $\begin{array}{l}34 \text { Fabricação e montagem de veículos automotores, } \\
\text { reboques e carrocerias }\end{array}$ & 5,64 & 5,76 & 44,35 & 53,29 & 20,17 & 2,06 \\
\hline 35 Fabricação de outros equipamentos de transporte & 0,77 & 1,52 & 34,93 & 64,64 & 85,03 & 8,47 \\
\hline
\end{tabular}


(conclusão)

\begin{tabular}{|c|c|c|c|c|c|c|}
\hline Classificação Nacional de Atividades Econômicas & $\begin{array}{l}\text { Participar } \\
1996\end{array}$ & $\begin{array}{l}\% \text { (PO) } \\
2007\end{array}$ & $\begin{array}{l}\text { Produtivid } \\
1996\end{array}$ & $\begin{array}{l}\text { ide R\$ mil } \\
2007\end{array}$ & $\begin{array}{l}\text { Crescimento } \\
2007 / 1996\end{array}$ & $\begin{array}{l}\text { Crescimento } \\
\text { Médio }\end{array}$ \\
\hline Alta tecnologia & 1,94 & 1,8 & 64,97 & 138,22 & 112,74 & 7,86 \\
\hline $\begin{array}{l}30 \text { Fabricação de máquinas para escritório e } \\
\text { equipamentos de informática }\end{array}$ & 0,30 & 0,61 & 63,70 & 201,39 & 216,16 & 13,15 \\
\hline $\begin{array}{l}32 \text { Fabricação de material eletrônico e de aparelhos e } \\
\text { equipamentos de comunicaçáo }\end{array}$ & 1,65 & 1,19 & 65,20 & 106,08 & 62,70 & 5,19 \\
\hline Total & 100,00 & 100,00 & 31,76 & 31,56 & $-0,62$ & 0,03 \\
\hline
\end{tabular}

Fonte: Elaboração dos autores com base nos dados do IBGE e da FGV, 2011.

de crescimento no período de 1996 a $2007 .{ }^{8}$

A taxa média de crescimento da produtividade no período analisado foi próxima a zero, sendo negativa nos anos de 2000 e de 2002 a 2005.

Assim, passado o primeiro momento, quando a abertura econômica proporcionou a modernização do parque industrial brasileiro, com ganhos de produtividade para a indústria, ${ }^{9}$ esses ganhos

\footnotetext{
${ }^{8}$ Os dados usados foram o Valor da Transformação Industrial (VTI) e o número de pessoas ocupadas (PO) na indústria, ambos retirados da PIA-IBGE, período de 1996 a 2007. Os dados foram deflacionados a preços de 1996 pelo índice de preços da indústria extrativa e de cada setor de atividade da indústria de transformação, calculado pela Fundação Getúlio Vargas (FGV). Para os setores que a FGV não divulga o Índice de Preços, foi utilizado o do setor
}

se dissiparam já no fim da década de 1990. Isso evidencia que as mudanças no cenário macroeconômico ocorridas na economia a partir da segunda metade dos anos 1990 não favoreceram o crescimento da produtividade do trabalho na indústria e mostra que o crescimento econômico não induziu a indústria a evoluir no que se refere ao nível tecnológico.

A Tabela 2 apresenta a participação de cada setor no emprego nacional, produtividade do trabalho a preços de 1996, a taxa de crescimento da produtividade do trabalho do ano de 2007 em relação ao ano de 1996, calculada com base nos dados regionais, e a média de crescimento do período de 1996 a 2007, valendo-se dos dados agregados em nível nacional. O crescimento do emprego total de 2007 em relaçáo a 1996 foi de 41,46\%, enquanto o crescimento do VTI foi de 40,58\%, resultando em crescimento negativo da produtividade do trabalho total $(-0,62)$. A média de crescimento na indústria de transformação foi 
de $-0,18 \%$, contrastando com as indústrias extrativas, onde o crescimento médio da produtividade foi de $5,18 \%$, com pequeno aumento na participaçáo do emprego total. Além da queda acumulada na produtividade real no período 1996-2007 de 0,62\%, observa-se que a participação dos setores no emprego mudou pouco de 1996 a 2007. Isso sinaliza que, apesar das transformações promovidas nos processos produtivos nos anos 1990 e 2000, a estrutura industrial se manteve relativamente rígida.

Do ponto de vista da produtividade dos 24 setores de atividade, em 13 a taxa média de crescimento foi negativa. Em termos dos grupamentos por intensidade tecnológica, todos apresentaram taxas médias negativas, à exceção do de alta tecnologia, sendo o setor de máquinas para escritório e equipamentos de informática o que apresentou maior percentual de expansão (13,15\%).

Em termos regionais, o crescimento da produtividade do trabalho de 2007 em relação a 1996 variou entre $-0,18 \%$ no Sudeste e 16,91\% no Norte. No entanto, é necessário considerar a participação de cada região no total do emprego nacional. Enquanto a região Sudeste participa com $53,69 \%$, a regiāo Norte participa com apenas 3,61\%.

$\mathrm{Na}$ avaliação do crescimento da produtividade do trabalho nos setores e nas regióes, deve-se levar em conta a mobilidade no emprego para saber se o aumento da produtividade do trabalho foi em razão da queda no emprego ou do aumento no valor agregado. A metodologia utilizada na avaliação empírica apresentada na seção seguinte deste trabalho leva em conta a participaçáo de cada setor e de cada regiáo no emprego nacional, conforme será visto na seção 4.2.

\section{4_Método estrutural diferencial modificado}

A decomposição do crescimento da produtividade regional no período 1996-2007 seguirá o método do shift-share. Essa técnica é bastante difundida em análises regionais, e seu método de análise está intimamente relacionado à análise de variância. Seu objetivo é descrever o crescimento econômico e/ou a produtividade de uma regiấo em termos de sua estrutura produtiva e de seu perfil regional. Existem muitas versôes desse método. ${ }^{10} \mathrm{Uma}$ das principais diferenças entre as diversas versões é a escolha do ano-base ou "peso": se o primeiro ano ou o último ano, ou ainda algum tipo de "média".

A aplicação do referido método neste estudo consiste em identificar quais setores ou regióes crescem relativamente mais rápido em comparação com outras
${ }^{10}$ Dunn (1959, 1960), Stilwell (1969), EstebanMaquillas (1972), Arcelus (1984), entre outros. 
regiōes, e se esse crescimento foi mais favorecido pelas mudanças na estrutura produtiva ou se pela própria competitividade da regiáo. De acordo com Haddad e Andrade (1989, p. 249), determinada região poderá apresentar ritmo de crescimento econômico maior do que o nacional ou porque na sua composição produtiva existe preponderância de setores mais dinâmicos, ou porque a região tem participação crescente na distribuição regional da produtividade, independentemente de sua expansão estar ocorrendo em setores dinâmicos ou não. Dessa forma, o modelo identifica as componentes de crescimento relacionadas com a estrutura da produtividade setorial e dos atributos de (des)vantagens locacionais da regiáo.

Lodder (1974, p. 55-56) explica que o grau de dinamismo de uma regiáo decorre de um fator estrutural e de outro diferencial; este se refere aos atributos da regiáo. $\mathrm{O}$ crescimento de uma regiáo pode ser explicado pela diferença entre o crescimento "real" e o que teria ocorrido caso crescesse segundo a taxa nacional. $\mathrm{O}$ fator estrutural reflete a composição setorial da regiáo, concentrado em setores economicamente dinâmicos ou não dinâmicos. O fator diferencial reflete as condiçôes da regiáo para a especialização em determinados setores, no sentido de que eles devem expandir-se mais rapidamente que a média nacional.
A formulação original da técnica do shift-share foi proposta por Dunn (1959, 1960). Essa técnica ancora-se em alguns supostos para a sua aplicação: estática comparativa; referência ao índice Laspeyres no que tange à ponderação pelo ano-base, assumindo que não há assimetrias importantes entre setores e regióes no ano-base; independência entre as componentes estrutural e regional; e assume-se que as atividades econômicas locais são influenciadas por fatores exógenos à região. A validade dos resultados apoia-se na propriedade de simetria de agregação e desagregação, propriedade que consiste na igualdade dos valores totais das componentes das amplitudes regional e setorial, com os resultados dos respectivos somatórios de cada setor e regiâo contidos na amplitude espacial.

Entre as suas limitaçooes, têm-se:

1) a hegemonia das influências exógenas sobre a região;

2) o problema da propriedade aditiva região-regiāo e setor-setor;

3) a questão da interdependência entre as componentes estrutural e regional;

4) o seu uso sob o método de estática comparativa;

5) a hipótese da constância da estrutura econômica no intervalo de tempo em 
estudo, gerando dificuldade para identificar o impacto de mudanças na composição setorial sobre o crescimento da regiáo.

Dado que vários autores discutiram essas limitaçóes, faz-se referência neste artigo aos seguintes autores: Arcelus (1984), que, desagregando a componente regional (diferencial), introduz no modelo as influências endógenas no crescimento da região; Haynes e Machunda (1987), que testaram a validade da aditividade das componentes do modelo de Arcelus, encerrando com a polêmica dessa propriedade; Esteban-Maquillas (1972), que introduziu no modelo a chamada "variável homotética", ${ }^{11}$ evitando a influência da componente estrutural sobre a regional (diferencial), bem como incorporou o efeito alocação (especialização), que possibilita captar as (des)vantagens competitivas de uma região em relaçáo a sua amplitude regional; Barff e Knight (1988), que propuseram uma análise dinâmica por meio da aplicação consecutiva de cada ano do período de análise; e a Stilwell (1969), ${ }^{12}$ que centrou sua preocupação em detectar possíveis mudanças estruturais no intervalo de tempo em análise de estática comparada.

\section{1_Descrição do modelo de Stilwell}

A análise shift-share se apoia em uma matriz de informaçóes de dada variável ba- se, que neste caso é a produtividade do trabalho regional/setorial, representada pela letra ' $R$ '. A matriz de informaçóes é formada em suas linhas pelos diversos setores de atividade e, nas colunas, pelas regiōes geográficas brasileiras.

\section{Tabela 3_Modelo de Matriz de Informações do Brasil}

\begin{tabular}{|c|c|c|}
\hline $\begin{array}{l}\text { Setores de } \\
\text { atividade }\end{array}$ & Regiões (j) & $\Sigma(\mathbf{j})$ \\
\hline (i) & R (ij) & $\Sigma R(i t)$ \\
\hline$\Sigma(i)$ & $\sum R(t j)$ & $\sum \boldsymbol{R}(t t)$ \\
\hline
\end{tabular}

Fonte: Elaborado pelos autores.

Partindo-se da versão de Dunn para o método estrutural-diferencial, o qual apresenta três componentes do crescimento, a Componente de Crescimento Global (CCG), a componente de Crescimento Estrutural (CCE) e a Componente de setor industrial das regióes do Reino Unido e demonstrou que a política regional dos anos 1960 adotada no país surtiu efeito em assegurar uma composição industrial mais benéfica nas regiōes menos desenvolvidas. Tal técnica subsidiou a adoção dessas políticas pelas autoridades governamentais. 
Crescimento Regional ou competitiva (CCR), temos:

$C C T=C C G+C C E+C C R$, onde

$$
C C T=R_{i j}^{0} \eta_{t t}+R_{i j}^{0}\left(\eta_{i t}-\eta_{t t}\right)+R_{i j}^{0}\left(\eta_{i j}-\eta_{i t}\right)
$$

$$
\mathrm{CCT}=\Delta \mathrm{R}_{\mathrm{ij}}=\mathrm{R}_{\mathrm{ij}}{ }^{0} \eta_{\mathrm{ij}}
$$

A Componente de Crescimento Total (CCT) é o resultado do desempenho das três componentes e representa a composição da variação do crescimento no período de cada setor e região. A CCG é igual ao acréscimo da produtividade que teria ocorrido se a regiáo crescesse à taxa de crescimento da produtividade nacional. A CCE, por sua vez, representa o montante adicional da produtividade que a regiáo poderá obter como resultante de sua composição setorial. Essa variação será positiva, se a região tiver se especializado em setores que apresentam altas taxas de crescimento da produtividade. A CCR indica o montante positivo (ou negativo) da produtividade que a região conseguirá em razão da taxa de crescimento da produtividade em determinados setores ser maior (ou menor) nessa regiâo em relação à média nacional.

Na versão descrita na equação (1), $\mathrm{R}^{0}$ corresponde à variável-base que neste caso é a produtividade do trabalho (R); $i$ representa os setores de atividades; $j$ representa as regióes; 0 corresponde ao pe- ríodo-base; 1 corresponde ao período corrente; $\eta_{t t}=\left(R_{t t}^{1} / R_{t t}^{0}\right)-1$ calcula a taxa de crescimento do valor da produtividade na amplitude espacial (Brasil), ponderado pelo ano-base; $\eta_{i t}=\left(R_{i t}^{1} / R_{i t}^{0}\right)-1$ calcula a taxa de crescimento do valor da produtividade no setor de atividade $i$ na amplitude regional (conjuntos das regióes), ponderado pelo ano-base; $\eta_{i j}=\left(R_{i j}^{1} / R_{i j}^{0}\right)-1$ calcula a taxa de crescimento do valor da produtividade no setor $i$ da regiáo $j$ (amplitude local), ponderado pelo ano-base.

A aplicação desse modelo para as regiōes do Brasil visa identificar as forças que explicam o crescimento regional desigual. A CCE identifica o crescimento desigual dos setores nas regióes. De acordo com Haddad e Andrade (1989), os fatores responsáveis por diferentes taxas de crescimento setorial em comparação ao nível nacional são: variação na estrutura da demanda, variação de produtividade, inovações tecnológicas, etc. O referido autor cita também que as principais forças que atuam no sentido de provocar esse crescimento são quase sempre de natureza locacional, tais como: variação nos custos de transporte, estímulos fiscais específicos para determinadas áreas, diferencial nos preços relativos de insumo entre regióes, etc.

Stilwell já havia apontado que o modelo descrito na equação (1) apresenta 
como limitação o fato de não considerar as mudanças estruturais na composição setorial das regióes durante o período observado. Uma regiāo especializada em setores menos dinâmicos no período inicial pode ter modificada a sua estrutura, de forma que, no período final, a sua composição setorial já tenha predominância relativamente maior de setores dinâmicos. A formulação de Stilwell, descrita na equação (2) e que será adotada na seção 4, objetivou corrigir tais limitaçóes. Esse autor faz um exame incremental da relaçáo entre crescimento regional e composição setorial.

$\mathrm{Na}$ formulação descrita na equação (2), insere-se uma taxa de crescimento revertida, em que se utiliza como referência o índice Paache em razão de a ponderação adotada ser do ano corrente. Pode-se observar o que ocorre quando se toma como referência a produtividade do trabalho do período corrente.
$\mathrm{Na}$ equação (2), $\lambda_{t t}=\left(R_{t t}^{0} / R_{t t}^{1}\right)-1$ corresponde à taxa de crescimento da produtividade na amplitude espacial ponderado pelo ano corrente; $\lambda_{i t}=\left(R_{i t}^{0} / R_{i t}^{1}\right)-1$ corresponde à taxa de crescimento do valor da produtividade no setor de atividade $i$ na amplitude regional (conjuntos das regiôes), ponderado pelo ano corrente.

A Componente de Crescimento Estrutural Modificada (CCEM) representa a diferença entre a Componente de Crescimento Estrutural Revertida (CCER) e a CCE e serve para indicar a variação líquida resultante de haver diferença entre as estruturas da produtividade das regióes entre o ano corrente e o ano-base. Da CCR da formulação de Dunn, foi subtraída a CCEM e obteve-se uma Componente de Crescimento Regional Residual (CCRR). Esse cálculo é necessário, porque a variação na estrutura econômica (composição setorial) é apenas uma das muitas

$$
\begin{aligned}
C C T & =C C G+C C E M+C C R R \\
C C T= & R_{i j}^{0} \eta_{t t}+\left(R_{i j}^{1}\left(\lambda_{t t}-\lambda_{i t}\right)-R_{i j}^{0}\left(\eta_{i t}-\eta_{t t}\right)\right)+\left(R_{i j}^{1}\left(\eta_{i j}-\eta_{i t}\right)-R_{i j}^{1}\left(\lambda_{t t}-\lambda_{i t}\right)-R_{i j}^{0}\left(\eta_{i t}-\eta_{t t}\right)\right) \\
C C E M & =C C E R-C C E \\
C C E M & =R_{i j}{ }^{1}\left(\lambda_{t t}-\lambda_{i t}\right)-R_{i j}{ }^{0}\left(\eta_{i t}-\eta_{t t}\right) \\
& C C R R=C C R-C C E M \\
& C C R R=R_{i j}{ }^{1}\left(\eta_{i j}-\eta_{i t}\right)-R_{i j}{ }^{1}\left(\lambda_{t t}-\lambda_{i t}\right)-R_{i j}{ }^{0}\left(\eta_{i t}-\eta_{t t}\right)
\end{aligned}
$$


influências sobre a variação no desempenho econômico da região, exigindo-se calcular as influências residuais de natureza regional.

Assim, a versão de Dunn é modificada por Stilwell (1969) de forma que possa levar em conta o impacto das mudanças estruturais sobre a variável em estudo (no nosso caso, a produtividade do trabalho regional) na composição setorial da produção durante o período estudado. A interpretação dessa mudança é observada por meio dos sinais das componentes, CCEM e CCRR. Se o sinal da CCEM for positivo, a regiáo modificou sua estrutura setorial de forma a se especializar mais nos setores de atividade cuja produção está crescendo mais rapidamente em nível nacional e menos nos setores cuja produção esteja crescendo lentamente em nível nacional. Se a CCRR for positiva, significa que a região cresceu por mérito próprio, ou seja, ela é competitiva, sem precisar contar com modificaçôes na especialização, mostrando que a CCR é maior do que a CCEM. Por fim, Stilwell (1970) argumenta que o método shift-share representa contribuição à teoria do crescimento regional, podendo ser amplamente utilizado na análise histórica de dados de emprego, produção e comércio, bem como para a previsão de crescimento regional.
Ademais, algumas informações são importantes na avaliação dos resultados. Não há regras para que as taxas de crescimento entre as amplitudes (local, regional, setorial e espacial) tenham necessariamente ascendência de uma sobre a outra. Dessa forma, as diferenças entre taxas para cada uma das componentes decompostas podem ser positivas (+) ou negativas (-), resultando, dessa maneira, que o somatório que gera a CCT pode ser tanto positivo como negativo.

O shift-share é um método que sinaliza para a influência maior ou menor do crescimento global (amplitude espacial), estrutural (configuração setorial) e regional (atributos da amplitude local) para um dado setor em uma dada regiáo (amplitude local). Se em alguns casos possa se apresentar uma aparente inconsistência, dado que se espera que a variável-base cresça com o mesmo sinal resultante da $\mathrm{CCT}_{\mathrm{ij}}$, observa-se que o diferencial das taxas de crescimento nos cálculos de cada componente e no total pode acompanhar o mesmo sinal ou náo, uma vez que se trata de um somatório de números relativos. Por tratar-se de uma decomposição acompanhada de cálculos de diferencial de taxas de crescimento, bem como nessa versão de Stilwell, em que se utiliza a base inicial R0 e também a base final R1 como referências para os cálculos das taxas de cresci- 
mento, é factível que a $\mathrm{CCT}_{\mathrm{ij}}$ possa ter sinais (+) ou (-) ocasionado por influência das componentes decompostas, e não da variação estrita da variável-base.

O objeto de estudo desse método é o de avaliar elementos representados pelas três componentes no resultado total de cada amplitude local $\left(\mathrm{CCT}_{\mathrm{ij}}\right)$, tratando-se, portanto, de uma análise de natureza estritamente de desempenho regional. ${ }^{13} \mathrm{O}$ método visa fazer diagnósticos de realidade regionais mostrando as causas. Contudo, o seu alcance não objetiva explicar essas causas. Cabe ao pesquisador conhecer a sua amplitude espacial, a composiçáo setorial e a regiáo em estudo.

A subseção abaixo faz uma adaptação na variável-base de modo a se tornar possível sua utilização no modelo. Apresenta-se também breve comentário das taxas de crescimento da produtividade do trabalho nos setores e nas regiōes, considerando sua participaçáo no emprego nacional. Tais taxas serão utilizadas na análise empírica em nível regional.

\section{2_Crescimento da produtividade do trabalho nas regiões: Contribuição de cada setor e de cada região para a produtividade do trabalho nacional}

Para aplicar o modelo apresentado, devemos ter uma matriz de informações na qual a soma das linhas representa os totais em cada regiáo, e a soma das colunas representa o total de cada setor de atividade no Brasil. ${ }^{14}$ Isso pode ser facilmente observado com a variável VTI ou com a variável $\mathrm{PO}$, mas não é notado na variável em estudo - a produtividade do trabalho -, que é simplesmente o resultado na divisáo entre as variáveis VTI e PO. Para aplicar o modelo, faz-se necessário usar algum tipo de ponderação, ou pelo VTI ou pela PO. Fagerberg $(2000)^{15}$ e Ro-
${ }^{13}$ É comum as pessoas confundirem o objeto de análise regional com um estudo da variável-base (tratase de uma proxy para a análise regional), ficando claro que o objeto de estudo do método shift-share não é a variávelbase, e sim as influências das escalas regionais; global (CCGij), regional (CCRRij), e estrutural (CCEMij), tratando- se de um método que induz a fazer diagnósticos de análise regional.

${ }^{14}$ Não encontramos registros de trabalhos utilizando a metodologia shift-share versão de Stilwell para aplicação em níveis regional e setorial empregando a variável produtividade do trabalho. Essa adaptação é uma tentativa de aplicaçáo dessa metodologia para o estudo em questão.

${ }^{15}$ Existem várias diferenças entre a metodologia de Stilwell (1969) e a apresentada por Fagerberg (2000). A versão de Stilwell utiliza uma matriz de informaçôes para análise em nível regional. Considera a influência da taxa de crescimento nacional sobre o crescimento das regióes. Na adaptação proposta, consideramos também a mobilidade da mão de obra entre os setores e entre as regióes do Brasil. As componentes de crescimento de Stilwell são diferentes da apresentada por Fagerberg. A versão de Fagerberg é mais utilizada para dados agregados em nível de país. 
${ }^{16}$ Uma tabela com a distribuição da produtividade do trabalho por setor e por regiáo no Brasil, considerando a participação no emprego nacional, está disponível mediante solicitação aos autores. cha (2007) optaram pela ponderação pela variável emprego (PO). Seguindo a notação adotada em Fagerberg (2000), temos:

$R_{i j}=\frac{V T I}{P O}=\frac{\sum V T I_{i j}}{\sum P O_{i j}}=\sum\left(\frac{V T I_{i j}}{P O_{i j}}-\frac{P O_{i j}}{\sum P O_{t t}}\right)$

$S i_{j}=\frac{P O_{i j}}{\sum P O_{t t}}$

$R=\sum\left(R_{i j}-S_{i j}\right)$

Nas equações acima, a variável $\mathrm{R}_{\mathrm{ij}}$ é a produtividade do trabalho de cada setor em cada região, e a variável $S_{i j}$ representa a participação de cada indústria em cada região no total do emprego. Assim, a variável $\mathrm{R}$ representa a produtividade do trabalho ponderada pela participação no total do emprego nacional. Desse modo, $R$ também representa a contribuição de cada setor e de cada regiáo para o resultado da produtividade nacional. ${ }^{16}$

Os dados por regiáo confirmam que a única região em que a produtividade do trabalho náo cresceu foi a Sudeste, onde a taxa foi negativa em 12,38\%, com queda na participação no emprego nacional de $12,23 \%$. O resultado da taxa de crescimento da produtividade negativa quando se considera a participação no emprego mostra que não houve incremento de valor agregado no total da indústria no Sudeste. As regióes menos desenvolvidas aumentaram sua participação no emprego nacional, e as taxas de crescimento do total das indústrias descritas na Tabela 4 sugerem que o aumento no emprego foi acompanhado por aumento no valor agregado nessas regióes.

Analisando-se por grupo quanto ao nível de tecnologia, nota-se que, no grupo de baixa tecnologia, para o total do Brasil, a taxa de decréscimo é maior $(-8,40)$ quando se considera a participação no emprego nacional, do que quando não se considera (-6,42). Esse grupo apresentou queda na participação percentual do emprego nacional. Nos grupos de média baixa e média alta tecnologia, houve ganho na participação percentual do emprego nacional. As taxas de decréscimo nesses grupos são menores quando se considera a participação no emprego nacional, do que quando náo se considera. $\mathrm{O}$ único grupo que apresentou taxa de crescimento da produtividade positiva - apesar da queda na participação percentual no emprego nacional - foi de alta tecnologia. Esse resultado indica que nesse grupo o crescimento da produtividade foi mais em razão do acréscimo no valor agregado.

O setor que apresentou maior taxa de crescimento da produtividade do trabalho no Brasil foi o de fabricaçáo de 
Tabela 4_Variação \% da produtividade do trabalho nos setores e regióes ponderadas pela participação no total do emprego nacional - 1996-2007

(continua)

\begin{tabular}{|c|c|c|c|c|c|c|}
\hline Classificação Nacional de Atividades Econômicas & $\mathbf{N}$ & NE & CO & $\mathbf{S}$ & SE & Brasil \\
\hline C Indústrias extrativas & 60,62 & 25,59 & 89,23 & $-40,49$ & 82,02 & 65,42 \\
\hline D Indústrias de transformação & 58,09 & 23,77 & 53,98 & 15,18 & $-15,60$ & $-2,54$ \\
\hline Baixa tecnologia & 25,56 & 12,18 & 60,15 & 3,63 & $-22,72$ & $-8,40$ \\
\hline 15 Fabricação de produtos alimentícios e bebidas & 42,07 & $-9,46$ & 66,83 & $-9,26$ & $-21,55$ & $-9,45$ \\
\hline 16 Fabricação de produtos do fumo & $\mathrm{X}$ & 142,77 & 157,27 & 74,42 & $-52,08$ & 5,35 \\
\hline 17 Fabricação de produtos têxteis & $-44,84$ & $-38,58$ & 152,59 & 1,59 & $-34,13$ & $-26,92$ \\
\hline 18 Confecção de artigos do vestuário e acessórios & 515,14 & 144,59 & 72,95 & 96,99 & 64,64 & 82,75 \\
\hline $\begin{array}{l}19 \text { Preparaçáo de couros e fabricaçáo de artefatos de couro, artigos de } \\
\text { viagem e calçados }\end{array}$ & 5484,64 & 199,14 & 219,80 & $-29,82$ & $-23,60$ & 0,54 \\
\hline 20 Fabricação de produtos de madeira & 12,49 & $-33,55$ & $-3,30$ & 12,71 & 12,37 & 9,80 \\
\hline 21 Fabricação de celulose, papel e produtos de papel & $-39,32$ & 38,81 & 152,51 & 1,46 & $-16,89$ & $-10,81$ \\
\hline 22 Edição, impressão e reprodução de gravaçóes & $-3,29$ & $-44,80$ & $-27,48$ & $-26,34$ & $-47,88$ & $-43,92$ \\
\hline 36 Fabricação de móveis e indústrias diversas & 30,79 & 89,05 & 154,06 & 13,45 & $-30,76$ & $-9,41$ \\
\hline 37 Reciclagem & $\mathrm{X}$ & 161,01 & $\mathrm{x}$ & 296,52 & 75,02 & 113,48 \\
\hline Média baixa tecnologia & 26,92 & 26,91 & $\mathbf{0 , 0 3}$ & 15,70 & $-17,93$ & $-8,69$ \\
\hline $\begin{array}{l}23 \text { Fabricação de coque, refino de petróleo, elaboração de } \\
\text { combustíveis nucleares e produçáo de álcool }\end{array}$ & 35,29 & 71,19 & $-74,15$ & 123,37 & $-5,89$ & 9,65 \\
\hline 25 Fabricação de artigos de borracha e plástico & $-20,43$ & 31,81 & 31,62 & $-3,36$ & $-36,64$ & $-27,33$ \\
\hline 26 Fabricação de produtos de minerais não metálicos & 151,21 & 12,14 & 0,96 & 0,74 & $-12,10$ & $-4,16$ \\
\hline 27 Metalurgia básica & 60,97 & $-21,68$ & 138,92 & 11,02 & $-9,53$ & $-5,55$ \\
\hline $\begin{array}{l}28 \text { Fabricação de produtos de metal - exceto máquinas e } \\
\text { equipamentos }\end{array}$ & $-15,22$ & 70,77 & 146,45 & 3,57 & $-29,93$ & $-19,85$ \\
\hline Média alta tecnologia & 103,14 & $-1,47$ & 150,30 & 30,70 & $-12,63$ & $-2,63$ \\
\hline 24 Fabricação de produtos químicos & 10,41 & $-21,98$ & 73,16 & 5,30 & $-33,73$ & $-26,93$ \\
\hline 29 Fabricação de máquinas e equipamentos & $-65,36$ & $-4,01$ & 171,78 & 1,89 & $-14,65$ & $-11,08$ \\
\hline 31 Fabricação de máquinas, aparelhos e material elétrico & 191,72 & $-35,26$ & 94,18 & $-3,93$ & $-31,79$ & $-25,28$ \\
\hline $\begin{array}{l}33 \text { Fabricação de equipamentos de instrumentação médico- } \\
\text { hospitalares, instrumentos de precisão e ópticos, equipamentos para } \\
\text { automação industrial, cronômetros e relógios }\end{array}$ & $-29,02$ & $-3,88$ & 1225,75 & 29,31 & 8,72 & 6,62 \\
\hline $\begin{array}{l}34 \text { Fabricação e montagem de veículos automotores, reboques e } \\
\text { carrocerias }\end{array}$ & 128,06 & 2191,10 & 1433,34 & 151,35 & 2,27 & 22,60 \\
\hline 35 Fabricação de outros equipamentos de transporte & 305,11 & 405,18 & 57,34 & 128,65 & 230,66 & 253,48 \\
\hline
\end{tabular}




\begin{tabular}{|c|c|c|c|c|c|c|}
\hline Classificação Nacional de Atividades Econômicas & $\mathbf{N}$ & NE & CO & S & SE & Brasil \\
\hline Alta tecnologia & 83,79 & 7492,16 & $-42,01$ & 198,73 & 42,48 & 96,66 \\
\hline $\begin{array}{l}30 \text { Fabricação de máquinas para escritório e equipamentos de } \\
\text { informática }\end{array}$ & 550,36 & 7739,27 & $-67,04$ & 2117,53 & 226,25 & 558,36 \\
\hline $\begin{array}{l}32 \text { Fabricação de material eletrônico e de aparelhos e } \\
\text { equipamentos de comunicação }\end{array}$ & 42,10 & 130,87 & 696,33 & 14,32 & $-1,86$ & 16,04 \\
\hline Outros & 55,30 & $-53,18$ & $-33,17$ & $-63,33$ & $\mathbf{x}$ & $-57,89$ \\
\hline Total & 58,33 & 23,89 & 55,54 & 14,62 & $-12,38$ & $-0,22$ \\
\hline
\end{tabular}

Fonte: Elaborado pelos autores com base nos dados da pesquisa.

máquinas e equipamentos de informática $(558,36 \%)$, sendo a região Nordeste a que exibiu maior crescimento $(7739,27 \%)$. A única região que não mostrou crescimento nesse setor foi a Centro-Oeste. O setor de equipamentos de transporte e veículos, reboques e carrocerias foi o segundo setor que mais cresceu no Brasil (253,48\%), e todas as regióes apresentaram altas taxas de crescimento nesse setor, sendo a maior taxa verificada também no Nordeste $(405,18 \%)$. O setor de artigos de vestuários e acessórios cresceu 82,75\% no Brasil, e também mostrou altas taxas de crescimento em todas as regióes, sendo a maior taxa verificada na regiāo Norte $(515,14 \%)$.

A indústria extrativa teve crescimento da produtividade de $65,41 \%$ no Brasil, sendo a regiáo Sudeste a que apresentou maior crescimento $(82,02 \%)$ nesse setor. As indústrias extrativas só não se expandiram na região Sul. As taxas nacionais negativas verificadas nos setores de edição, impressão e reprodução de gravaçóes $(-43,92 \%)$ e fabricação de produtos químicos $(-26,93 \%)$ foram acompanhadas por queda no emprego, o que mostra que também não houve incremento de valor nesses setores.

\section{5_Análise dos resultados do shift-share}

A análise das três componentes de crescimento do modelo - global (CGC), estrutural modificada (CCEM), e regional residual (CCRR) - que formam a componente total (CCT) - mostra qual das componentes teve mais peso na taxa de crescimento 
Tabela 5_Decomposição da taxa de crescimento da produtividade do trabalho por região - 1996-2007

\begin{tabular}{|c|c|c|c|c|c|}
\hline & SE & $\mathbf{S}$ & $\mathbf{N}$ & NE & CO \\
\hline Valor em R\$ da Componente de Crescimento Global - CCG & $-54,69$ & $-13,98$ & $-3,64$ & $-6,07$ & $-1,77$ \\
\hline Participação \% da CCG na CCT & $(-2,11)$ & $-1,32$ & $-1,04$ & $-0,85$ & $-0,45$ \\
\hline Crescimento \% por causa da CCG & $-0,26$ & $-0,19$ & $-0,6$ & $-0,2$ & $-0,25$ \\
\hline $\begin{array}{l}\text { Valor em R\$ da Componente de Crescimento Estrutural } \\
\text { Modificada - CCEM }\end{array}$ & $-246,68$ & 89,67 & $-3,86$ & 233,65 & $-72,79$ \\
\hline Participação \% da CCEM na CCT & $(-9,53)$ & 8,49 & $-1,1$ & 32,85 & $-18,65$ \\
\hline Crescimento \% por causa da CCEM & $-1,18$ & 1,24 & $-0,64$ & 7,85 & $-10,36$ \\
\hline $\begin{array}{l}\text { Valor em R\$ da Componente de Crescimento Regional } \\
\text { Residual - CCRR }\end{array}$ & $-2.287,53$ & 979,95 & 359,1 & 483,64 & 464,85 \\
\hline Participação \% da CCRR na CCT & $(-88,36)$ & 92,83 & 102,13 & 68 & 119,1 \\
\hline Crescimento \% por causa da CCRR & $-10,94$ & 13,57 & 59,57 & 16,25 & 66,15 \\
\hline Valor em R\$ da Componente de Crescimento Total - CCT & $-2.588,91$ & $1.055,64$ & 351,6 & 711,23 & 390,29 \\
\hline Participação \% total & $(100)$ & 100 & 100 & 100 & 100 \\
\hline Crescimento \% da produtividade do trabalho & $-12,38$ & 14,62 & 58,33 & 23,89 & $5,5,5$ \\
\hline
\end{tabular}

Fonte: Elaborado pelos autores com base nos dados daw pesquisa.

* Nota: Os valores entre parênteses na tabela são percentuais de um valor negativo; quanto maior o valor, maior a retraçáo do crescimento da produtividade do trabalho.

da produtividade do trabalho em cada regiâo. A Tabela 5 apresenta os resultados ${ }^{17}$ agregados da decomposição do crescimento da produtividade do trabalho pelo método shift-share para as regiôes.

A componente de crescimento global, como apresentado anteriormente, detecta o acréscimo que teria o valor da produtividade do trabalho da regiáo, caso a taxa de crescimento de $2007 \mathrm{em}$ relação a 1996 fosse a mesma taxa nacional $(-0,22 \%)$. Essa componente reflete a simples induçâo do crescimento nacio- nal sobre o desempenho da regiáo. Como a taxa de crescimento nacional foi negativa e próxima a zero, a componente de crescimento global é negativa em todas as regióes e demonstrou ser a componente de menor peso. Tal componente mostra que a influência da mudança estrutural foi negativa nas regióes Norte e Centro-Oeste (além da Sudeste), e que as mudanças estruturais favoreceram mais as regiōes Nordeste e Sul. Esse resultado expressa em parte que o grau de integração da indústria entre as regióes do
${ }_{17}$ Alguns problemas como, por exemplo, a ausência ou a omissão de dados de alguns setores em nível regional, por ventura podem ter influenciado os resultados para alguns setores de atividade.

No entanto, os resultados para as regiōes, em geral, estáo de acordo com o esperado. 
país não se modificou muito no período, e que as mudanças na estrutura produtiva pouco contribuíram para o crescimento da produtividade do trabalho.

A Componente de Crescimento Regional Residual (CCRR) foi superior em relaçâo às demais, indicando que o crescimento da produtividade do trabalho foi maior em razão das vantagens locacionais e competitivas regionais do que das mudanças estruturais na composição setorial (com exceção da regiâo Sudeste).

Destaca-se que a Componente de Crescimento Total (CCT) só foi negativa para o Sudeste. O desempenho negativo da produtividade do trabalho nacional no período se deveu principalmente ao fato de que todas as componentes da taxa de crescimento da produtividade na região Sudeste - região que detém a maior participação na indústria - foram negativas. A perda de eficiência da indústria nacional no período é explicada pelo recuo da produtividade na região mais industrializada do país. As regióes Sul e Nordeste foram as que apresentaram a componente total com maior valor em relação às demais. Esse resultado se deu pelo fato de as componentes estrutural modificada e regional residual terem contribuído positivamente para explicar a produtividade dessas regióes. No entanto, o crescimento da produtivi- dade do trabalho observado nas regióes menos desenvolvidas foi insuficiente para compensar o decréscimo obtido na região Sudeste.

$\mathrm{Na}$ sequência são apresentados os resultados da decomposiçáo da taxa de crescimento por setor de atividade para cada uma das regióes. O percentual de cada uma das componentes apresentados revela quanto cada componente explica da taxa de crescimento em cada setor de atividade. Tal percentual também representa a participaçáo de cada componente na taxa de crescimento da produtividade do trabalho de cada setor de atividade.

\section{1_Região Sudeste}

A queda no crescimento da produtividade do trabalho na regiáo Sudeste foi explicada em $88,36 \%$ pela componente regional residual. A componente estrutural modificada justifica $9,53 \%$.

O resultado mais importante é que a região Sudeste foi a única em que a componente regional residual foi negativa, indicando que a produtividade do trabalho na região Sudeste não foi favorecida pelas suas condiçóes de competitividade regional. Tal resultado é coerente com a teoria das deseconomias de escala.

Faz-se uma leitura dos resultados para a indústria extrativa com o propósito de servir de guia para os demais setores. 
Tabela 6A_Participação do emprego no total do setor, taxa de crescimento da produtividade do trabalho considerando a participação no emprego nacional e resultados da decomposição da taxa de crescimento da produtividade do trabalho (1996-2007) - Região Sudeste

\begin{tabular}{|c|c|c|c|c|c|c|}
\hline Classificação Nacional de Atividades Econômicas & $\begin{array}{l}\text { Part.P0 } \\
2007\end{array}$ & $\begin{array}{l}\text { Taxa de } \\
\text { Cresc.em \% }\end{array}$ & CCG & cipação \% na & $\begin{array}{l}\text { CCT } \\
\text { CCRR }\end{array}$ & $\begin{array}{l}\text { Valor R\$ } \\
\text { CCT }\end{array}$ \\
\hline C Indústrias extrativas & 59,25 & 82,02 & $-1,55$ & 41,44 & 60,11 & 116,27 \\
\hline D Indústrias de transformação & 53,56 & $-15,60$ & & & & \\
\hline Baixa Tecnologia & & $-22,72$ & & & & \\
\hline 15 Fabricação de produtos alimentícios e bebidas & 53,56 & $-21,55$ & $(2,05)$ & $(-9,78)$ & $(107,73)$ & $-384,12$ \\
\hline 16 Fabricação de produtos do fumo & 32,47 & $-52,08$ & $(0,44)$ & $(5,28)$ & $(94,28)$ & $-104,00$ \\
\hline 17 Fabricação de produtos têxteis & 54,82 & $-34,13$ & $(3,40)$ & $(-34,43)$ & $(131,04)$ & $-50,25$ \\
\hline 18 Confecção de artigos do vestuário e acessórios & 46,86 & 64,64 & $(1,38)$ & $(43,75)$ & $(54,86)$ & $-75,26$ \\
\hline $\begin{array}{l}19 \text { Preparação de couros e fabricação de artefatos de } \\
\text { couro, artigos de viagem e calçados }\end{array}$ & 30,00 & $-23,60$ & $(1,04)$ & $(0,77)$ & $(98,19)$ & $-52,60$ \\
\hline 20 Fabricação de produtos de madeira & 21,29 & 12,37 & $-10,94$ & 11,29 & 99,65 & 1,95 \\
\hline 21 Fabricação de celulose, papel e produtos de papel & 58,00 & $-16,89$ & $(4,00)$ & $(-10,97)$ & $(106,97)$ & $-54,11$ \\
\hline 22 Edição, impressão e reproduçáo de gravações & 61,36 & $-47,88$ & $(6,02)$ & $(-70,72)$ & $(164,71)$ & $-53,36$ \\
\hline 36 Fabricação de móveis e indústrias diversas & 48,32 & $-30,76$ & $(1,17)$ & $(-9,90)$ & $(108,73)$ & $-92,38$ \\
\hline 37 Reciclagem & 68,41 & 75,02 & $(1,11)$ & $(48,08)$ & $(50,80)$ & $-2,54$ \\
\hline Média Baixa Tecnologia & & $-17,93$ & & & & \\
\hline $\begin{array}{l}23 \text { Fabricação de coque, refino de petróleo, elaboração } \\
\text { de combustíveis nucleares e produção de álcool }\end{array}$ & 64,72 & $-5,89$ & $(1,67)$ & $(8,23)$ & $(90,10)$ & $-168,86$ \\
\hline 25 Fabricação de artigos de borracha e plástico & 61,99 & $-36,64$ & $(2,65)$ & $(-35,65)$ & $(133,00)$ & $-93,09$ \\
\hline 26 Fabricação de produtos de minerais não metálicos & 53,84 & $-12,10$ & $(3,10)$ & $(-3,84)$ & $(100,75)$ & $-58,32$ \\
\hline 27 Metalurgia básica & 73,81 & $-9,53$ & $(5,98)$ & $(-4,96)$ & $(98,99)$ & $-59,47$ \\
\hline $\begin{array}{l}28 \text { Fabricação de produtos de metal - exceto } \\
\text { máquinas e equipamentos }\end{array}$ & 65,32 & $-29,93$ & $(2,45)$ & $(-23,42)$ & $(120,97)$ & $-95,90$ \\
\hline Média Alta Tecnologia & & $-12,63$ & & & & \\
\hline 24 Fabricação de produtos químicos & 70,07 & $-33,73$ & $(3,60)$ & $(-34,33)$ & $(130,73)$ & $-211,22$ \\
\hline 29 Fabricação de máquinas e equipamentos & 65,26 & $-14,65$ & $(6,62)$ & $(-10,68)$ & $(104,05)$ & $-59,02$ \\
\hline $\begin{array}{l}31 \text { Fabricação de máquinas, } \\
\text { aparelhos e material elétrico }\end{array}$ & 67,97 & $-31,79$ & $(3,75)$ & $(-31,38)$ & $(127,63)$ & $-45,64$ \\
\hline
\end{tabular}




\begin{tabular}{|c|c|c|c|c|c|c|}
\hline Classificação Nacional de Atividades Econômicas & $\begin{array}{l}\text { Part.P0 } \\
2007\end{array}$ & $\begin{array}{l}\text { Taxa de } \\
\text { Cresc.em \% }\end{array}$ & CCE & $\begin{array}{l}\text { cipação \% na } \\
\text { CĆ.ं }\end{array}$ & $\begin{array}{l}\text { CCT } \\
\text { CCRR }\end{array}$ & $\begin{array}{l}\text { Valor R\$ } \\
\text { CCT }\end{array}$ \\
\hline $\begin{array}{l}33 \text { Fabricação de equipamentos de instrumentação } \\
\text { médico-hospitalares, instrumentos de precisão e } \\
\text { ópticos, equipamentos para automação industrial, } \\
\text { cronômetros e relógios }\end{array}$ & 73,29 & 8,72 & $-13,74$ & 8,31 & 105,44 & 3,21 \\
\hline $\begin{array}{l}34 \text { Fabricação e montagem de veículos automotores, } \\
\text { reboques e carrocerias }\end{array}$ & 71,47 & 2,27 & $(1,23)$ & $(18,18)$ & $(80,59)$ & $-462,28$ \\
\hline 35 Fabricação de outros equipamentos de transporte & 72,08 & 230,66 & $(1,10)$ & $(68,38)$ & $(30,52)$ & $-39,94$ \\
\hline Alta Tecnologia & & 42,48 & & & & \\
\hline $\begin{array}{l}30 \text { Fabricação de máquinas para escritório e } \\
\text { equipamentos de informática }\end{array}$ & 58,85 & 226,25 & $(0,08)$ & $(84,57)$ & $(15,35)$ & $-446,87$ \\
\hline $\begin{array}{l}32 \text { Fabricação de material eletrônico e de aparelhos e } \\
\text { equipamentos de comunicaçáo }\end{array}$ & 53,58 & $-1,86$ & $(1,40)$ & $(13,65)$ & $(84,95)$ & $-101,15$ \\
\hline Total & 53,69 & $-12,38$ & $(2,11)$ & $(9,53)$ & $(88,36)$ & $-2588,91$ \\
\hline
\end{tabular}

Fonte: Elaborado pelos autores com base nos dados da pesquisa.

Nota: Os valores entre parênteses na tabela são percentuais de um valor da CCT setorial negativo; quanto maior o percentual, maior a retraçăo do crescimento da produtividade do trabalho. Neste caso, os percentuais negativos entre parênteses correspondem a componentes positivas.

A indústria extrativa no Sudeste respondeu por 59,25\% do emprego do setor em 2007. O crescimento da produtividade do trabalho do ano de 2007 em relação ao ano de 1996 foi de 82,02\%. A componente global explicou $-1,55 \%$ desse crescimento, a componente estrutural modificada, $41,44 \%$, e a componente regional residual, $60,11 \%$.

No período de análise, nota-se que ocorreu na regiáo crescimento da parti- cipação relativa da indústria extrativa, principalmente a relacionada a petróleo e gás. A indústria extrativa aumentou em termos relativos sua produtividade tanto em relação à média das demais regióes quanto em relação à média nacional.

Analisando-se por setor de atividade, a componente total só foi positiva em três setores: indústria extrativa; no setor de produtos de madeira, no qual a componente global explicou -10,94\%; a com- 
ponente estrutural modificada, $11,29 \%$; e a regional residual, 99,65\%; e no setor de equipamentos de instrumentação médico-hospitalares, no qual a componente global explicou $-13,74 \%$; a componente estrutural modificada, $8,31 \%$; e a regional residual, $105,44 \%$ do crescimento da produtividade do trabalho.

Os setores que tiveram maior peso no resultado negativo da componente total foram produtos alimentícios e bebidas; produtos químicos; coque, refino de petróleo, elaboração de combustíveis nucleares e produção de álcool; produtos do fumo; e material eletrônico e de aparelhos e equipamentos de comunicação Apesar de os setores de máquinas para escritório e equipamentos de informática e de montagem de veículos automotores, reboques e carrocerias também terem apresentado resultado da componente total negativa, não podemos dizer que tais setores contribuíram para a retração, uma vez que apresentaram taxas de crescimento da produtividade do trabalho positivas.

Os resultados para alguns setores parecem mostrar aparente inconsistência, dado que se espera que a produtividade do trabalho cresça com o mesmo sinal resultante da CCTij. No entanto, como enfatizado na seção 4.1, se observa que o diferencial das taxas de crescimento nos cálculos de cada componente e no total pode ou não acompanhar o mesmo sinal, já que se trata de um somatório de números relativos.

Os sinais das componentes totais e das taxas de crescimento da produtividade do trabalho foram diferentes em cinco setores - confecção de artigos de vestuários e acessórios; máquinas para escritório e equipamentos de informática; montagem de veículos automotores, reboques e carrocerias; outros equipamentos de transporte; e reciclagem. Nesses casos, a taxa de crescimento foi positiva, porém todas as três componentes - global, estrutural e regional - foram negativas. Com exceção do setor de reciclagem, todos os demais citados tiveram crescimento do VTI superior ao crescimento do emprego; no entanto, nos setores de confecção de artigos de vestuários e acessórios, e montagem de veículos automotores, reboques e carrocerias houve queda da participação no emprego nacional.

\subsection{Região Sul}

$\mathrm{Na}$ regiáo Sul, tanto o total da componente regional residual como o da estrutural modificada foram positivas. A componente regional residual explicou $92,83 \%$ do crescimento da produtivida- 
de do trabalho, e a componente estrutural modificada, 8,49\%.

A componente estrutural modificada foi positiva em oito setores, porém só foi superior à componente regional residual no setor fabricação de máquinas para escritório e equipamentos de informática - setor onde a produtividade cresceu mais -, no qual a componente estrutural modificada foi responsável por $85,17 \%$ do crescimento da produtividade. $\mathrm{O}$ segundo setor em que a produtividade mais cresceu foi o de reciclagem, no qual a componente estrutural modificada explicou $49,85 \%$ do crescimento. Outro setor importante na regiáo e que foi favorecido pelas mudanças estruturais foi o de confecção de artigos do vestuário e acessórios, no qual a componente estrutural modificada foi responsável por $47,86 \%$ do crescimento.

A componente regional residual foi positiva em 19 setores, sendo superior a 100\% em 11 setores. No setor de montagem de veículos automotores, reboques e carrocerias - setor representativo na regiáo e que teve crescimento expressivo da produtividade do trabalho, sendo o terceiro onde a produtividade mais cresceu -,, a componente regional residual foi responsável por $81,42 \%$ do crescimento da produtividade. $\mathrm{O}$ setor de coque, refino de petróleo e combustíveis foi o quarto no ranking do crescimento da produtividade. Neste setor, a componente regional explicou $91,66 \%$ do crescimento.

Em cinco setores, a taxa de crescimento da produtividade do trabalho apresentou sinal diferente da componente total. Os setores de material eletrônico e de aparelhos e equipamentos de comunicação e outros equipamentos de transporte mostraram taxas de crescimento positivas; contudo, a componente total foi negativa. Nesses setores, o crescimento do VTI foi superior ao crescimento do emprego. No primeiro caso, houve queda da participação do setor no emprego nacional, e, no segundo, houve aumento da participação do setor no emprego nacional.

O oposto ocorreu nos setores impressão e reprodução de gravaçóes; artigos de borracha e plástico; máquinas, aparelhos e material elétrico. Nesses casos, os setores apresentaram componentes regionais positivas, indicando que o setor foi favorecido pelas condiçóes regionais. No entanto, parece não ter sido suficiente para compensar a retração sofrida em virtude das mudanças estruturais negativas observadas. Nesses setores, o crescimento do VTI foi inferior ao crescimento do emprego, e a participação dos setores no emprego nacional teve aumento. 
Tabela 6B_Participação do emprego total do setor, taxa de crescimento da produtividade do trabalho considerando a participação no emprego nacional e resultados da decomposição da taxa de crescimento da produtividade do trabalho (1996-2007) - Região Sul

(continua)

\begin{tabular}{|c|c|c|c|c|c|c|}
\hline \multirow[b]{2}{*}{ Classificação Nacional de Atividades Econômicas } & \multirow{2}{*}{$\begin{array}{l}\text { Part.P0 } \\
2007\end{array}$} & \multirow{2}{*}{$\begin{array}{l}\text { Taxa de } \\
\text { Cresc.em \% }\end{array}$} & \multicolumn{3}{|c|}{ Participação \% na CCT } & \multirow{2}{*}{$\begin{array}{l}\text { Valor R\$ } \\
\text { CCT }\end{array}$} \\
\hline & & & CCG & CCEM & CCRR & \\
\hline C Indústrias extrativas & 10,11 & $-40,49$ & $(0,24)$ & $(39,55)$ & $(60,21)$ & $-58,98$ \\
\hline D Indústrias de transformação & 25,63 & 15,18 & & & & \\
\hline Baixa Tecnologia & & 3,63 & & & & \\
\hline 15 Fabricação de produtos alimentícios e bebidas & 25,47 & $-9,26$ & $(400,08)$ & $(67,44)$ & $(-367,52)$ & $-0,80$ \\
\hline 16 Fabricação de produtos do fumo & 45,11 & 74,42 & $-0,37$ & 5,37 & 95,00 & 99,15 \\
\hline 17 Fabricação de produtos têxteis & 25,67 & 1,59 & $-0,90$ & $-37,16$ & 138,06 & 57,04 \\
\hline 18 Confecçáo de artigos do vestuário e acessórios & 30,77 & 96,99 & $-1,81$ & 47,86 & 53,95 & 30,84 \\
\hline $\begin{array}{l}19 \text { Preparação de couros e fabricação de artefatos de } \\
\text { couro, artigos de viagem e calçados }\end{array}$ & 40,75 & $-29,82$ & $(0,83)$ & $(0,77)$ & $(98,40)$ & $-124,56$ \\
\hline 20 Fabricação de produtos de madeira & 48,06 & 12,71 & $-9,51$ & 11,00 & 98,51 & 4,43 \\
\hline 21 Fabricação de celulose, papel e produtos de papel & 28,80 & 1,46 & $-2,11$ & $-12,34$ & 114,45 & 28,52 \\
\hline 22 Edição, impressão e reprodução de gravaçóes & 20,00 & $-26,34$ & $-1,46$ & $-79,84$ & 181,30 & 23,82 \\
\hline 36 Fabricação de móveis e indústrias diversas & 36,87 & 13,45 & $-1,12$ & $-10,35$ & 111,47 & 51,36 \\
\hline 37 Reciclagem & 29,53 & 296,52 & $-0,13$ & 49,85 & 50,28 & 2,43 \\
\hline Média Baixa Tecnologia & & 15,70 & & & & \\
\hline $\begin{array}{l}23 \text { Fabricação de coque, refino de petróleo, elaboração } \\
\text { de combustíveis nucleares e produção de álcool }\end{array}$ & 9,70 & 123,37 & $-0,22$ & 8,56 & 91,66 & 105,74 \\
\hline 25 Fabricação de artigos de borracha e plástico & 23,67 & $-3,36$ & $-1,07$ & $-38,05$ & 139,12 & 49,61 \\
\hline 26 Fabricação de produtos de minerais não metálicos & 20,31 & 0,74 & $-5,45$ & $-4,53$ & 109,98 & 9,31 \\
\hline 27 Metalurgia básica & 13,83 & 11,02 & $-1,55$ & $-5,79$ & 107,34 & 15,97 \\
\hline $\begin{array}{l}28 \text { Fabricação de produtos de metal - exceto máquinas } \\
\text { e equipamentos }\end{array}$ & 23,48 & 3,57 & $-1,09$ & $-24,99$ & 126,08 & 48,54 \\
\hline Média Alta Tecnologia & & 30,70 & & & & \\
\hline 24 Fabricação de produtos químicos & 13,63 & 5,30 & $-0,79$ & $-37,11$ & 137,90 & 120,47 \\
\hline 29 Fabricação de máquinas e equipamentos & 28,51 & 1,89 & $-1,99$ & $-12,66$ & 114,66 & 68,20 \\
\hline 31 Fabricação de máquinas, aparelhos e material elétrico & 22,31 & $-3,93$ & $-1,20$ & $-34,28$ & 135,48 & 29,51 \\
\hline $\begin{array}{l}33 \text { Fabricação de equipamentos de instrumentação } \\
\text { médico-hospitalares, instrumentos de precisão e ópticos, } \\
\text { equipamentos para automação industrial, cronômetros } \\
\text { e relógios }\end{array}$ & 18,83 & 29,31 & $-1,13$ & 6,62 & 94,51 & 10,39 \\
\hline
\end{tabular}




\begin{tabular}{|c|c|c|c|c|c|c|}
\hline Classificação Nacional de Atividades Econômicas & $\begin{array}{l}\text { Part.P0 } \\
2007\end{array}$ & $\begin{array}{l}\text { Taxa de } \\
\text { Cresc.em \% }\end{array}$ & Part & $\begin{array}{l}\text { cipação \% ne } \\
\text { cCEM }\end{array}$ & $\begin{array}{l}\text { CCT } \\
\text { CCRR }\end{array}$ & $\begin{array}{l}\text { (conclusão) } \\
\text { Valor R\$ } \\
\text { CCT }\end{array}$ \\
\hline $\begin{array}{l}34 \text { Fabricação e montagem de veículos automotores, } \\
\text { reboques e carrocerias }\end{array}$ & 23,71 & 151,35 & $-0,20$ & 18,77 & 81,42 & 312,16 \\
\hline 35 Fabricação de outros equipamentos de transporte & 4,95 & 128,65 & $(0,20)$ & $(71,26)$ & $(28,54)$ & $-7,99$ \\
\hline Alta Tecnologia & & 198,73 & & & & \\
\hline $\begin{array}{l}30 \text { Fabricação de máquinas para escritório e } \\
\text { equipamentos de informática }\end{array}$ & 19,61 & 2117,53 & $-0,02$ & 85,17 & 14,85 & 192,05 \\
\hline $\begin{array}{l}32 \text { Fabricação de material eletrônico e de aparelhos e } \\
\text { equipamentos de comunicaçáo }\end{array}$ & 13,10 & 14,32 & $(12,89)$ & $(10,17)$ & $(76,94)$ & $-2,52$ \\
\hline Outros & 19,06 & $-63,33$ & 4,47 & $-128,52$ & 224,06 & $-9,04$ \\
\hline Total & 25,27 & 14,62 & $-1,32$ & 8,49 & 92,83 & 1055,64 \\
\hline
\end{tabular}

Fonte: Elaborado pelos autores com base nos dados da pesquisa.

Nota: Os valores entre parênteses na tabela são percentuais de um valor da CCT setorial negativo, quanto maior o percentual, maior a retraçấo do crescimento da produtividade do trabalho. Neste caso, os percentuais negativos entre parênteses correspondem a componentes positivas.

\subsection{Região Norte}

Os resultados para a regiáo Norte revelam que a componente regional residual explicou $102,13 \%$ do crescimento da produtividade do trabalho, e as demais componentes - global e estrutural modificada - tiveram contribuição negativa.

Apesar de o total da componente estrutural modificada ser negativo, alguns setores foram favorecidos pela mudança estrutural na composição setorial. No setor de outros equipamentos de transporte, a componente estrutural foi responsável por $73,58 \%$ do crescimento da produtividade do trabalho. Já no setor de confecção de artigos do vestu- ário e acessórios, sua contribuição foi de $45,64 \%$, e, no setor de montagem de veículos automotores, reboques e carrocerias, foi de $18,80 \%$.

A componente regional residual foi positiva em 16 setores, sendo superior a $100 \%$ em nove deles, compensando, assim, o resultado total negativo das componentes global e estrutural modificada.

No setor de material eletrônico e de aparelhos e equipamentos de comunicação, a componente regional residual foi responsável por $86,61 \%$ do crescimento da produtividade do trabalho. Esse setor de alta tecnologia emprega $32,28 \%$ do emprego do setor e representa $15,45 \%$ do 
Tabela 6C_Participação do emprego no total do setor, taxa de crescimento da produtividade do trabalho considerando a participação no emprego nacional e resultados da decomposição da taxa de crescimento da produtividade do trabalho (1996-2007) - Região Norte

\begin{tabular}{|c|c|c|c|c|c|c|}
\hline$\cdots \cdots \cdots \cdots \cdots \cdots \cdots \cdots$ & Part.PO & Cresc.em \% & Par & cipação \% I & CCT & Valor $\mathbf{R} \mathbf{S}$ \\
\hline Classificação Nacional de Atividades Econômicas & & & CCE & CCEM & CCRR & \\
\hline C Indústrias extrativas & 5,72 & 60,62 & $(5,01)$ & $(34,50)$ & $(60,49)$ & $-6,73$ \\
\hline D Indústrias de transformação & 3,56 & 58,09 & & & & \\
\hline Baixa Tecnologia & & 25,56 & & & & \\
\hline 15 Fabricação de produtos alimentícios e bebidas & 3,63 & 42,07 & $-0,49$ & $-10,28$ & 110,77 & 113,50 \\
\hline 17 Fabricação de produtos têxteis & 0,84 & $-44,84$ & $(1,39)$ & $(-35,55)$ & $(134,16)$ & $-1,13$ \\
\hline 18 Confecção de artigos do vestuário e acessórios & 0,64 & 515,14 & $-0,06$ & 45,64 & 54,42 & 4,43 \\
\hline $\begin{array}{l}19 \text { Preparação de couros e fabricação de artefatos de couro, } \\
\text { artigos de viagem e calçados }\end{array}$ & 0,37 & 5484,64 & 0,00 & 0,79 & 99,22 & 8,20 \\
\hline 20 Fabricação de produtos de madeira & 19,57 & 12,49 & $-10,42$ & 11,19 & 99,23 & 1,56 \\
\hline 21 Fabricação de celulose, papel e produtos de papel & 2,66 & $-39,32$ & $(0,88)$ & $(-11,68)$ & $(110,79)$ & $-10,35$ \\
\hline 22 Edição, impressão e reprodução de gravaçóes & 3,68 & $-3,29$ & $-0,63$ & $-78,80$ & 179,43 & 20,96 \\
\hline 36 Fabricação de móveis e indústrias diversas & 2,50 & 30,79 & $-0,63$ & $-10,25$ & 110,89 & 10,28 \\
\hline Média Baixa Tecnologia & & 26,92 & & & & \\
\hline $\begin{array}{l}23 \text { Fabricação de coque, refino de petróleo, elaboração de } \\
\text { combustíveis nucleares e produção de álcool }\end{array}$ & 0,23 & 35,29 & $-2,02$ & 8,89 & 93,13 & 8,89 \\
\hline 25 Fabricação de artigos de borracha e plástico & 3,66 & $-20,43$ & $-3,81$ & $-39,76$ & 143,57 & 3,03 \\
\hline 26 Fabricação de produtos de minerais não metálicos & 4,74 & 151,21 & $-0,16$ & $-4,10$ & 104,27 & 26,32 \\
\hline 27 Metalurgia básica & 3,37 & 60,97 & $-0,38$ & $-5,66$ & 106,04 & 36,07 \\
\hline $\begin{array}{l}28 \text { Fabricação de produtos de metal - exceto máquinas e } \\
\text { equipamentos }\end{array}$ & 1,96 & $-15,22$ & $-5,80$ & $-27,10$ & 132,90 & 2,49 \\
\hline Média Alta Tecnologia & & 103,14 & & & & \\
\hline 24 Fabricação de produtos químicos & 1,51 & 10,41 & $-0,68$ & $-37,05$ & 137,73 & 11,32 \\
\hline 29 Fabricação de máquinas e equipamentos & 0,66 & $-65,36$ & $(0,46)$ & $(-12,09)$ & $(111,63)$ & $-30,79$ \\
\hline 31 Fabricação de máquinas, aparelhos e material elétrico & 3,06 & 191,72 & $-0,12$ & $-33,64$ & 133,75 & 17,09 \\
\hline $\begin{array}{l}33 \text { Fabricação de equipamentos de instrumentação médico- } \\
\text { hospitalares, instrumentos de precisão e ópticos, equipamentos } \\
\text { para automação industrial, cronômetros e relógios }\end{array}$ & 3,94 & $-29,02$ & $(0,71)$ & $(6,37)$ & $(92,92)$ & $-14,42$ \\
\hline $\begin{array}{l}34 \text { Fabricação e montagem de veículos automotores, } \\
\text { reboques e carrocerias }\end{array}$ & 0,43 & 128,06 & $-0,24$ & 18,80 & 81,44 & 3,56 \\
\hline 35 Fabricação de outros equipamentos de transporte & 19,05 & 305,11 & $-0,49$ & 73,58 & 26,91 & 42,91 \\
\hline
\end{tabular}




\begin{tabular}{|c|c|c|c|c|c|c|}
\hline & Part.po & Cresc.em \% & Part & cipação \% n & CCT & Valor R\$ \\
\hline Classificação Nacional de Atividades Econômicas & 2007 & Prod. Trab. & CCG & CCEM & CCRR & CCT \\
\hline Alta Tecnologia & & 83,79 & & & & \\
\hline $\begin{array}{l}30 \text { Fabricação de máquinas para escritório e equipamentos } \\
\text { de informática }\end{array}$ & 14,11 & 550,36 & $(3,07)$ & $(65,19)$ & $(31,74)$ & $-2,87$ \\
\hline $\begin{array}{l}32 \text { Fabricaçáo de material eletrônico e de aparelhos e } \\
\text { equipamentos de comunicaçáo }\end{array}$ & 32,28 & 42,10 & $-0,98$ & 14,37 & 86,61 & 100,27 \\
\hline Outros & 26,77 & 55,30 & $-0,22$ & $-137,81$ & 238,03 & 6,98 \\
\hline Total & 3,61 & 58,33 & $-1,04$ & $-1,10$ & 102,13 & 351,60 \\
\hline
\end{tabular}

Fonte: Elaborado pelos autores com base em dados da pesquisa.

Nota: Os valores entre parênteses na tabela são percentuais de um valor da CCT setorial negativo, quanto maior o percentual, maior a retraçăo do crescimento da produtividade do trabalho. Neste caso, os percentuais negativos entre parênteses correspondem a componentes positivas.

\footnotetext{
${ }^{18}$ Um estudo da Zona Franca de Manaus pode ser visto em Lyra, 1995.

A criação da ZFM foi uma forma de se criarem no país outras oportunidades de investimento e lucratividade para as empresas nacional e estrangeira, e também foi uma estratégia e uma tática de dinamização das forças produtivas regionais que consistiu na redução do custo Amazônia.
}

emprego na região, e por isso é considerado o setor mais importante na regiāo. Cabe destacar que o desenvolvimento da indústria, principalmente a de alta tecnologia, no Amazonas, foi favorecido pelos incentivos fiscais oriundos das políticas advindas da criação da Zona Franca de Manaus, em 1957, e regulamentada em $1967,{ }^{18}$ a qual também foi responsável pelo processo de desenvolvimento da região.

No grupo de baixa tecnologia, os setores mais representativos são o de pro- dutos alimentícios e bebidas, no qual a componente regional foi responsável por $110,77 \%$ do crescimento, e no setor de produtos de madeira, a componente regional foi responsável por 99,23\% do crescimento.

O setor de calçados foi o que teve crescimento maior da produtividade, seguido pelo setor de vestuários. No entanto, apesar do expressivo desenvolvimento, esses dois setores juntos responderam por apenas 2\% do emprego em 2007 dessa 
regiáo. $\mathrm{O}$ mesmo ocorre com o setor de montagem de veículos automotores, reboques e carrocerias, que teve crescimento da produtividade de $128,06 \%$, mas tabém não é um setor expressivo na região. É igualmente importante destacar o crescimento em setores de média alta e alta tecnologia no Norte, principalmente os setores de máquinas para escritório e equipamentos de informática e material eletrônico e de aparelhos e equipamentos de comunicação. Cabe a observação de que as taxas de crescimento para esses setores foram baseadas apenas nos dados do Estado do Amazonas, uma vez que, para os demais Estados, os dados estavam incompletos ou foram omitidos.

Em cinco setores, a taxa de crescimento da produtividade do trabalho teve sinal diferente da componente total. $\mathrm{Na}$ indústria extrativa e no setor de máquinas para escritório e equipamentos de informática, a taxa de crescimento foi positiva; porém, a componente total foi negativa. Nesses setores, o crescimento do VTI foi superior ao do emprego. No primeiro caso, houve queda da participação do setor no emprego nacional, e, no segundo, houve aumento da participação do setor no emprego nacional.

O oposto ocorreu nos setores de edição, impressão e reprodução de gravaçóes. artigos de borracha e plástico, e pro- dutos de metal. Nesses casos, os setores tiveram componente regional positiva, indicando que tais setores foram favorecidos pelas condições regionais. No entanto, parece não ter sido suficiente para compensar a retração sofrida em virtude das mudanças estruturais negativas. Nesses, o crescimento do VTI foi inferior ao crescimento do emprego, e houve acréscimo da participação desses setores no emprego nacional.

\subsection{Região Nordeste}

Na regiáo Nordeste, tanto a componente regional residual como a estrutural modificada foram positivas. A componente regional residual explicou 68\% do crescimento da produtividade do trabalho, e a componente estrutural modificada, $32,85 \%$.

A componente estrutural modificada foi positiva em nove setores, dos quais em três ela foi superior à componente regional residual. A componente estrutural modificada foi responsável por 85,09\% do crescimento no setor de máquinas para escritório e equipamentos de informática, sendo esse o setor que mais cresceu. No setor de outros equipamentos de transporte, ela foi responsável por $72,52 \%$ do crescimento, e no setor de reciclagem, por $51,76 \%$ do crescimento da produtividade do trabalho. 
A componente regional residual foi positiva em 16 setores. No setor de couros e fabricação de artefatos de couro, artigos de viagem e calçados - setor com maior representatividade na região -, a componente regional residual foi responsável por $99,34 \%$ do crescimento da produtividade do trabalho. Outro setor representativo na região é o de coque, refino de petróleo, elaboração de combustíveis, no qual a componente regional residual foi responsável por $91,81 \%$ do crescimento da produtividade do trabalho. $\mathrm{O}$ segundo setor que mais cresceu foi o de montagem de veículos automotores, reboques e carrocerias, no qual a componente regional residual foi responsável por $81,32 \%$ do crescimento da produtividade do trabalho.

Em três setores, a taxa de crescimento da produtividade do trabalho teve sinal diferente da componente total. A indústria extrativa registrou crescimento positivo, porém a componente regional foi negativa. O VTI cresceu acima do emprego; mesmo assim o setor registrou aumento da participação no emprego nacional. O oposto ocorreu nos setores de produtos químicos e máquinas e equipamentos. Nesses casos, os setores apresentaram componente regional positiva, indicando que tais setores foram favorecidos pelas condiçóes regionais. No entanto, parece não ter sido suficiente para compensar a retração sofrida em virtude das mudanças estruturais. Nesses setores, o crescimento do VTI foi inferior ao do emprego. No entanto, o setor de produtos químicos registrou queda da participação no emprego nacional.

Como visto, a mudança estrutural foi fundamental para o crescimento de $7.739,27 \%$ do setor de máquinas para escritório e equipamentos de informática. Há de se destacar que nesse setor o crescimento da produtividade foi baseado principalmente nos dados do Estado da Bahia, uma vez que, no Estado de Pernambuco, o crescimento da produtividade foi negativo nesse setor, e os demais estados tiveram dados omitidos. Em relação ao setor de material eletrônico e de aparelhos e equipamentos de comunicação, o crescimento de $130,87 \%$ foi baseado nos dados do Estado do Ceará.

A regiâo Nordeste foi a que mais se beneficiou relativamente com as mudanças na composição setorial. Isso indica que a regiâo modificou sua estrutura setorial de forma a se especializar mais em alguns setores de atividade cuja produção está crescendo mais rapidamente em nível nacional, e menos nos setores cuja produção cresce lentamente em nível nacional. 
Tabela 6D_Participação do emprego no total do setor, taxa de crescimento da produtividade do trabalho considerando a participação no emprego nacional e resultados da decomposição da taxa de crescimento da produtividade do trabalho (1996-2007) - Regiáo Nordeste

\begin{tabular}{|c|c|c|c|c|c|c|}
\hline Classificação Nacional de Atividades Econômicas & $\begin{array}{l}\text { Part.P0 } \\
2007\end{array}$ & $\begin{array}{l}\text { Taxa de } \\
\text { Cresc.em \% }\end{array}$ & $\begin{array}{l}\text { Participaçãa } \\
\text { CCCG }\end{array}$ & $\begin{array}{l}\% \text { na CCT } \\
\text { CCEM }\end{array}$ & CCRR & $\begin{array}{l}\text { (continua) } \\
\text { Valor } \mathbf{R} \$ \\
\text { CCT }\end{array}$ \\
\hline C Indústrias extrativas & 20,45 & 25,59 & $(0,63)$ & $(39,13)$ & $(60,23)$ & $-60,60$ \\
\hline D Indústrias de transformação & 12,49 & 23,77 & & & & \\
\hline Baixa Tecnologia & & 12,18 & & & & \\
\hline 15 Fabricação de produtos alimentícios e bebidas & 20,53 & $-9,46$ & $(96,45)$ & $(8,51)$ & $(-4,97)$ & $-1,61$ \\
\hline 16 Fabricação de produtos do fumo & 21,84 & 142,77 & $-0,18$ & 5,35 & 94,83 & 3,96 \\
\hline 17 Fabricação de produtos têxteis & 17,09 & $-38,58$ & $(2,13)$ & $(-35,24)$ & $(133,11)$ & $-20,87$ \\
\hline 18 Confecção de artigos do vestuário e acessórios & 17,19 & 144,59 & $-0,41$ & 46,06 & 54,35 & 40,59 \\
\hline $\begin{array}{l}19 \text { Preparação de couros e fabricação de artefatos de } \\
\text { couro, artigos de viagem e calçados }\end{array}$ & 26,79 & 199,14 & $-0,13$ & 0,79 & 99,34 & 153,81 \\
\hline 20 Fabricaçáo de produtos de madeira & 2,63 & $-33,55$ & $(0,58)$ & $(9,07)$ & $(90,35)$ & $-4,18$ \\
\hline 21 Fabricação de celulose, papel e produtos de papel & 8,74 & 38,81 & $-0,51$ & $-11,98$ & 112,50 & 28,38 \\
\hline 22 Edição, impressão e reprodução de gravações & 10,09 & $-44,80$ & $(22,34)$ & $(-50,96)$ & $(128,62)$ & $-0,82$ \\
\hline 36 Fabricação de móveis e indústrias diversas & 8,54 & 89,05 & $-0,26$ & $-10,18$ & 110,44 & 20,19 \\
\hline 37 Reciclagem & 2,05 & 161,01 & $-0,41$ & 51,76 & 48,65 & 0,08 \\
\hline Média Baixa Tecnologia & & 26,91 & & & & \\
\hline $\begin{array}{l}23 \text { Fabricação de coque, refino de petróleo, elaboração } \\
\text { de combustíveis nucleares e produção de álcool }\end{array}$ & 18,41 & 71,19 & $-0,41$ & 8,60 & 91,81 & 100,00 \\
\hline 25 Fabricaçáo de artigos de borracha e plástico & 8,10 & 31,81 & $-0,43$ & $-37,64$ & 138,07 & 30,72 \\
\hline 26 Fabricação de produtos de minerais não metálicos & 15,59 & 12,14 & $-1,58$ & $-4,22$ & 105,80 & 17,36 \\
\hline 27 Metalurgia básica & 6,64 & $-21,68$ & $(1,55)$ & $(-5,45)$ & $(103,90)$ & $-23,78$ \\
\hline $\begin{array}{l}28 \text { Fabricação de produtos de metal } \\
\text { - exceto máquinas e equipamentos }\end{array}$ & 5,83 & 70,77 & $-0,28$ & $-24,64$ & 124,92 & 25,58 \\
\hline Média Alta Tecnologia & & $-1,47$ & & & & \\
\hline 24 Fabricação de produtos químicos & 9,71 & $-21,98$ & $-5,40$ & $-40,02$ & 145,42 & 23,16 \\
\hline 29 Fabricação de máquinas e equipamentos & 4,61 & $-4,01$ & $-3,73$ & $-13,07$ & 116,80 & 3,99 \\
\hline $\begin{array}{l}31 \text { Fabricação de máquinas, } \\
\text { aparelhos e material elétrico }\end{array}$ & 5,87 & $-35,26$ & $(2,48)$ & $(-32,11)$ & $(129,63)$ & $-4,94$ \\
\hline $\begin{array}{l}33 \text { Fabricação de equipamentos de instrumentação } \\
\text { médico-hospitalares, instrumentos de precisão e } \\
\text { ópticos, equipamentos para automação industrial, } \\
\text { cronômetros e relógios }\end{array}$ & 3,44 & $-3,88$ & $(2,34)$ & $(6,10)$ & $(91,56)$ & $-0,54$ \\
\hline
\end{tabular}




\begin{tabular}{|c|c|c|c|c|c|c|}
\hline Classificação Nacional de Atividades Econômicas & $\begin{array}{l}\text { Part.po } \\
2007\end{array}$ & $\begin{array}{l}\text { Taxa de } \\
\text { Cresc.em \% }\end{array}$ & $\begin{array}{l}\text { Participação } \\
\text { cĆ }\end{array}$ & $\begin{array}{l}\% \text { na CCT } \\
\text { CCEM }\end{array}$ & CCRR & $\begin{array}{l}\text { Valor R\$ } \\
\text { CCT }\end{array}$ \\
\hline $\begin{array}{l}34 \text { Fabricação e montagem de veículos automotores, } \\
\text { reboques e carrocerias }\end{array}$ & 2,94 & 2191,10 & $-0,01$ & 18,70 & 81,32 & 101,26 \\
\hline 35 Fabricação de outros equipamentos de transporte & 3,26 & 405,18 & $-0,17$ & 72,52 & 27,65 & 6,19 \\
\hline Alta Tecnologia & & 7492,16 & & & & \\
\hline $\begin{array}{l}30 \text { Fabricação de máquinas para escritório e } \\
\text { equipamentos de informática }\end{array}$ & 6,58 & 7739,27 & 0,00 & 85,09 & 14,92 & 271,64 \\
\hline $\begin{array}{l}32 \text { Fabricação de material eletrônico e de aparelhos e } \\
\text { equipamentos de comunicação }\end{array}$ & 0,12 & 130,87 & $-0,21$ & 13,70 & 86,52 & 0,15 \\
\hline Outros & 41,71 & $-53,18$ & $-5,68$ & $-148,65$ & 254,33 & 1,50 \\
\hline Total & 12,68 & 23,89 & $-0,85$ & 32,85 & 68,00 & 711,23 \\
\hline
\end{tabular}

Fonte: Elaborado pelos autores com base nos dados da pesquisa.

Nota: Os valores entre parênteses na tabela são percentuais de um valor da CCT setorial negativo, quanto maior o percentual, maior a retração do crescimento da produtividade do trabalho. Neste caso, os percentuais negativos entre parênteses correspondem a componentes positivas.

\subsection{Regiáo Centro-Deste}

A indústria na região Centro-Oeste se beneficiou com as vantagens locacionais. Neste sentido, a componente regional residual explicou $119,10 \%$ do crescimento da produtividade do trabalho, e as demais componentes - global e estrutural modificada - tiveram contribuição negativa.

Apesar de o total da componente estrutural modificada ser negativo, em al- guns setores ela contribuiu positivamente para o crescimento da produtividade do trabalho. $\mathrm{Na}$ indústria extrativa, a componente estrutural modificada foi responsável por $40,94 \%$ do crescimento. Já no setor de montagem de veículos automotores, sua contribuição foi de $18,70 \%$, e no setor de material eletrônico e de aparelhos e equipamentos de comunicação, de $14 \%$. 
Tabela 6E_Participação do emprego no total do setor, taxa de crescimento da produtividade do trabalho considerando a participação no emprego nacional e resultados da decomposição da taxa de crescimento da produtividade do trabalho (1996-2007) - Regiáo Centro-Deste

\begin{tabular}{|c|c|c|c|c|c|c|}
\hline Classificação Nacional de Atividades Econômicas & $\begin{array}{l}\text { Part.P0 } \\
2007\end{array}$ & $\begin{array}{l}\text { Taxa de } \\
\text { Cresc.em \% }\end{array}$ & CCG & $\begin{array}{l}\text { cipação \% } \\
\text { cCEM }\end{array}$ & $\begin{array}{l}\text { CCT } \\
\text { CCRR }\end{array}$ & $\begin{array}{l}\text { (continua) } \\
\text { Valor R\$ } \\
\text { CCT }\end{array}$ \\
\hline C Indústrias extrativas & 4,47 & 89,23 & $-1,08$ & 40,94 & 60,14 & 7,28 \\
\hline D Indústrias de transformação & 4,76 & 53,98 & & & & \\
\hline Baixa Tecnologia & & 60,15 & & & & \\
\hline 15 Fabricação de produtos alimentícios e bebidas & 10,93 & 66,83 & $-0,33$ & $-10,25$ & 110,58 & 258,98 \\
\hline 16 Fabricação de produtos do fumo & 0,57 & 157,27 & $-0,17$ & 5,41 & 94,76 & 0,05 \\
\hline 17 Fabricação de produtos têxteis & 1,57 & 152,59 & $-0,14$ & $-36,67$ & 136,81 & 12,49 \\
\hline 18 Confecção de artigos do vestuário e acessórios & 4,55 & 72,95 & $(2,52)$ & $(42,33)$ & $(55,15)$ & $-2,43$ \\
\hline $\begin{array}{l}19 \text { Preparaçáo de couros e fabricação de artefatos de couro, } \\
\text { artigos de viagem e calçados }\end{array}$ & 2,10 & 219,80 & $-0,12$ & 0,79 & 99,33 & 13,36 \\
\hline 20 Fabricação de produtos de madeira & 8,45 & $-3,30$ & $(1,90)$ & $(8,81)$ & $(89,29)$ & $-4,66$ \\
\hline 21 Fabricação de celulose, papel e produtos de papel & 1,80 & 152,51 & $-0,16$ & $-11,90$ & 112,06 & 4,55 \\
\hline 22 Edição, impressão e reproduçáo de gravações & 4,87 & $-27,48$ & $-1,57$ & $-79,99$ & 181,55 & 5,45 \\
\hline 36 Fabricação de móveis e indústrias diversas & & 154,06 & $-0,16$ & $-10,16$ & 110,32 & 8,75 \\
\hline Média Baixa Tecnologia & & $\mathbf{0 , 0 3}$ & & & & \\
\hline $\begin{array}{l}23 \text { Fabricação de coque, refino de petróleo, elaboração de } \\
\text { combustíveis nucleares e produção de álcool }\end{array}$ & 6,94 & $-74,15$ & $(0,30)$ & $(8,47)$ & $(91,22)$ & $-49,57$ \\
\hline 25 Fabricação de artigos de borracha e plástico & 2,58 & 31,62 & $-0,43$ & $-37,64$ & 138,07 & 6,46 \\
\hline 26 Fabricação de produtos de minerais não metálicos & 5,51 & 0,96 & $-5,22$ & $-4,52$ & 109,73 & 2,55 \\
\hline 27 Metalurgia básica & 2,35 & 138,92 & $-0,18$ & $-5,64$ & 105,81 & 26,85 \\
\hline $\begin{array}{l}28 \text { Fabricação de produtos de metal - exceto máquinas e } \\
\text { equipamentos }\end{array}$ & 3,42 & 146,45 & $-0,15$ & $-24,57$ & 124,72 & 16,16 \\
\hline Média Alta Tecnologia & & 150,30 & & & & \\
\hline 24 Fabricação de produtos químicos & 5,08 & 73,16 & $-0,25$ & $-36,77$ & 137,02 & 46,27 \\
\hline 29 Fabricação de máquinas e equipamentos & 0,96 & 171,78 & $-0,14$ & $-12,23$ & 112,37 & 12,03 \\
\hline 31 Fabricação de máquinas, aparelhos e material elétrico & 0,80 & 94,18 & $-0,21$ & $-33,80$ & 134,01 & 1,76 \\
\hline $\begin{array}{l}33 \text { Fabricaçáo de equipamentos de instrumentação médico- } \\
\text { hospitalares, instrumentos de precisáo e ópticos, equipamentos } \\
\text { para automação industrial, cronômetros e relógios }\end{array}$ & 0,51 & 1225,75 & $-0,02$ & 6,50 & 93,52 & 0,67 \\
\hline $\begin{array}{l}34 \text { Fabricação e montagem de veículos automotores, } \\
\text { reboques e carrocerias }\end{array}$ & 1,43 & 1433,34 & $-0,02$ & 18,70 & 81,32 & 38,97 \\
\hline 35 Fabricação de outros equipamentos de transporte & 0,66 & 57,34 & $(0,13)$ & $(71,41)$ & $(28,46)$ & $-1,86$ \\
\hline
\end{tabular}




\begin{tabular}{|c|c|c|c|c|c|c|}
\hline Classificação Nacional de Atividades Econômicas & $\begin{array}{l}\text { Part.P0 } \\
2007\end{array}$ & $\begin{array}{l}\text { Taxa de } \\
\text { Cresc.em \% }\end{array}$ & CCG Part & $\begin{array}{l}\text { cipação \% \% } \\
\text { сCEM }\end{array}$ & $\begin{array}{l}\text { a CCT } \\
\text { CCRR }\end{array}$ & $\begin{array}{l}\text { lconclusão } \\
\text { Valor } \mathbf{R} \$ \\
\text { CCT }\end{array}$ \\
\hline Alta Tecnologia & & $-42,01$ & & & & \\
\hline $\begin{array}{l}30 \text { Fabricação de máquinas para escritório e equipamentos } \\
\text { de informática }\end{array}$ & 0,85 & $-67,04$ & $(0,04)$ & $(84,78)$ & $(15,18)$ & $-14,43$ \\
\hline $\begin{array}{l}32 \text { Fabricaçáo de material eletrônico e de aparelhos e } \\
\text { equipamentos de comunicaçáo }\end{array}$ & 0,92 & 696,33 & $-0,04$ & 14,00 & 86,04 & 0,53 \\
\hline Outros & 12,47 & $-33,17$ & $-1,07$ & $-143,29$ & 244,35 & 0,05 \\
\hline Total & 4,75 & 55,54 & $-0,45$ & $-18,65$ & 119,10 & 390,29 \\
\hline
\end{tabular}

Fonte: Elaborado pelos autores com base nos dados da pesquisa.

Nota: Os valores entre parênteses na tabela são percentuais de um valor da CCT setorial negativo, quanto maior o percentual, maior a retração do crescimento da produtividade do trabalho. Neste caso, os percentuais negativos entre parênteses correspondem a componentes positivas.

A componente regional residual foi positiva em 18 setores, sendo as contribuiçóes para a taxa de crescimento superiores a 100\% em 12 setores, compensando, assim, o resultado negativo das componentes global e estrutural modificada. No setor de produtos alimentícios e bebidas, por exemplo, a contribuição da componente regional residual para o crescimento da produtividade foi de 110,58\%.

A produtividade do trabalho cresceu mais no setor de montagem de veículos automotores, reboques e carrocerias, em que a componente regional residual explicou $81,32 \%$ do crescimento. O segundo setor que mais cresceu foi o de instrumentos médico-hospitalares, onde a componente regional residual explicou $93,52 \%$ do crescimento. Nesse setor, o re- sultado foi baseado nos dados do Estado de Goiás. Já no caso do setor de material eletrônico e de aparelhos e equipamentos de comunicação, onde a componente regional residual justificou $86,04 \%$, o resultado foi baseado nos dados dos Estados de Goiás e Distrito Federal. O resultado negativo no setor de equipamentos de informática foi baseado nos dados do Distrito Federal.

Em três setores de atividade, o sinal da taxa de crescimento da produtividade do trabalho foi diferente da componente total. Nos setores de confecção de artigos de vestuários e acessórios e outros equipamentos de transporte, a taxa de crescimento da produtividade do trabalho foi positiva, mas a componente total foi negativa. $\mathrm{O}$ crescimento do VTI foi 
superior ao crescimento do emprego. No entanto, no primeiro caso houve acréscimo da participação do setor no emprego nacional. $\mathrm{O}$ oposto ocorreu no setor de edição, impressão e reprodução de gravaçóes. Nesse, a componente regional foi positiva, indicando que o setor foi favorecido pelas condiçóes regionais. No entanto, parece não ter sido suficiente para compensar a retração sofrida em virtude das mudanças estruturais negativas observadas. Também o crescimento do VTI foi inferior ao crescimento do emprego, mas, mesmo assim, houve decréscimo da participação do setor no emprego nacional.

\subsection{Resultados gerais}

A partir de 1999, todas as regióes apresentaram expansão da mão de obra empregada na indústria, comportamento que parece se diferenciar do observado até o fim dos anos 1990, quando a manutenção dos ganhos de produtividade foi obtida com contração do emprego. Tal comportamento confirma a hipótese de que os ganhos de produtividade nos anos 1990 foram em grande parte em razão de um choque de oferta propiciado pela abertura comercial que expôs o setor a um ambiente mais competitivo. A eliminação de unidades menos produtivas, aliada à incorporação pela indústria de novas técnicas e processos de produ- ção e de materiais mais eficientes, possibilitou que a produtividade industrial, que havia estagnado na segunda metade dos anos 1980, voltasse a crescer. No início, no entanto, a recuperação da produtividade implicou eliminação de postos de trabalho e recuo no emprego industrial. Uma vez esgotados os benefícios dos ganhos marginais obtidos pelas melhorias nos processos de produção, a indústria voltou a expandir, ainda que modestamente, o emprego nos anos 2000.

Comparando-se as componentes de crescimento nos diversos setores e regiōes, observa-se que os valores da componente regional residual apresentaram maior dispersão entre os setores e regióes do que em relação à componente estrutural modificada, indicando que as vantagens locacionais na produtividade dos setores explicaram mais as variaçóes na produtividade do trabalho entre as regióes do que mudanças na estrutura produtiva no período.

Do ponto de vista setorial, o segmento de fabricação de máquinas para escritório e equipamentos de informática nas regióes Nordeste e Sul apresentou valores positivos tanto para a componente estrutural modificada quanto para a componente regional residual. No entanto, como a estrutural modificada foi superior à regional nesses casos, isso mostra que fo- 
${ }_{19}$ Uma abordagem sobre intervenção estatal e desigualdade regional pode ser vista em Monteiro NT. (2006). ram as mudanças na estrutura produtiva que contribuíram com a maior parcela do crescimento da produtividade do trabalho nesse setor nas regióes Nordeste e Sul.

Em resumo, comparando-se as componentes estrutural modificada e a regional residual nos diversos setores e regióes, podemos deduzir que o crescimento nesses anos se deu mais por causa da componente regional residual, ou seja, da competitividade dos próprios setores nas regiôes, com exceção de alguns deles, principalmente o de equipamentos de informática, conforme mencionado.

Os valores da componente total reforçam os resultados obtidos em relação ao desempenho da produtividade do trabalho. Comparando-se as taxas de crescimento com os valores da componente total, nota-se que, em $83,3 \%$ dos casos, a componente total foi positiva nos setores em que as taxas de crescimento da produtividade do trabalho foram positivas.

É importante destacar que, na regiāo Norte, a indústria se beneficiou de incentivos fiscais oriundos das políticas voltadas ao desenvolvimento da Zona Franca de Manaus. As regióes Norte, Nordeste e Centro-Oeste contam com uma fonte a mais para financiamento das atividades produtivas, que são os fundos constitucionais de financiamento ${ }^{19}$ (FNO, FNE e FCO). Tais fundos cons- tituem um diferencial para essas regióes e podem contribuir para impulsionar o crescimento industrial nessas regiōes.

Os resultados gerais mostram que houve certo rearranjo de alguns setores da indústria entre as regióes. No entanto, as regiōes menos desenvolvidas ainda não conseguem absorver aquela parcela dos setores em declínio na região Sudeste. O grau de integração entre as regióes e o grau de desenvolvimento ou absorção tecnológica das regióes menos desenvolvidas parecem ser insuficientes para impulsionar o crescimento da produtividade do trabalho em nível nacional. A região Sudeste perdeu eficiência, visto que sofreu deseconomias de escala, e os ganhos das demais regiôes não compensaram tal decréscimo. Isso resultou em uma taxa de crescimento da produtividade do trabalho negativa em nível nacional. Houve deseconomias de escala na região mais representativa, e os ganhos das demais regióes não foram suficientes para compensar as perdas.

Uma importante consideração a ser feita é que a análise por grandes regióes geográficas apresenta algumas dificuldades, seja pela dimensão territorial, seja pela diversidade natural, econômica e social dentro das grandes regióes. No caso da regiáo Sudeste, por exemplo, os resultados encontrados na análise do método são bem diferentes quando se faz a aná- 
lise para cada um dos Estados. Somente o de São Paulo apresenta decréscimo, enquanto os demais Estados da região $\mathrm{Su}$ deste apresentam taxas de crescimento da produtividade do trabalho positivas. Isso está de acordo com as análises de Diniz e Crocco (1996, p. 77), os quais defendem que, nos últimos anos, a análise regional se tornou ainda mais problemática, uma vez que houve ampliação dessas diferenças dentro de cada região ou Estado. Conforme os autores, no caso de Sáo Paulo, por exemplo, tais diferenças estariam associadas aos processos de reversão de polarização e reconcentração regional dentro do Estado e à natureza, às vezes contraditória, do crescimento industrial dentro de cada Estado, onde existem áreas de crescimento industrial acelerado e áreas estagnadas ou decadentes.

\section{Considerações finais}

A teoria estabelece que políticas de abertura comercial possam exercer efeito positivo sobre o crescimento da produtividade, por meio da indução de mudanças tecnológicas. No entanto, o efeito da abertura sobre a economia das regióes pode ser ambíguo se a abertura náo provocar mudança estrutural na direção da produção de bens com mais conteúdo tecnológico. As regióes com vantagens compara- tivas nos setores intensivos em pesquisa e tecnologia tendem a se beneficiar mais com a abertura econômica. Ocorre que, no Brasil, a região mais desenvolvida sofre um processo de deseconomia de escala, e o crescimento nas demais regióes ainda é insuficiente para compensar o decréscimo ocorrido na região mais representativa.

A produtividade do trabalho no Brasil (R\$31,52 mil a preços de 1996) em 2007 está praticamente no mesmo nível do ano de 1996. Alguns setores de alta tecnologia tiveram crescimento expressivo no período, ampliando a participação no VTI total da indústria; por exemplo, o setor de equipamentos de informática teve taxa média de crescimento nacional de $13,15 \%$ a.a no período analisado. A produtividade do trabalho nacional nesse setor passou de $\mathrm{R} \$ 63,70$ mil em 1996 para R\$201,39 mil, e sua participaçáo no VTI nacional passou de $0,59 \%$ para $3,87 \%$. Outros exemplos são os setores de equipamentos de transporte, equipamentos de comunicação, coque refino de petróleo e combustíveis, os quais também apresentaram crescimento expressivo na produtividade do trabalho. Por outro lado, setores importantes como o de produtos químicos, metalurgia básica, minerais não metálicos e produtos de metal não tiveram bom desempe- 
nho, sendo a produtividade do trabalho nestes dois últimos setores muito abaixo da média nacional.

Este trabalho traz uma contribuição para o debate sobre o comportamento da produtividade do trabalho nos setores de atividade da indústria de transformação nas regióes do Brasil ao explorar o método shift-share de decomposição da taxa de crescimento da produtividade do trabalho. Essa técnica é bastante difundida em análises regionais, já que descreve o crescimento da produtividade de uma região em termos de sua estrutura produtiva e de seu perfil regional. Apesar da importância do tema, são poucos os estudos disponíveis que avaliam o comportamento da produtividade do trabalho na indústria em níveis regional e setorial, sendo esse o diferencial do artigo. A ponderação da produtividade do trabalho de cada setor e região por sua respectiva participação no emprego nacional mostrou a contribuição de cada setor e regiāo para a produtividade do trabalho total ou nacional.

Os resultados da decomposição da taxa de crescimento da produtividade do trabalho mostraram que, na maioria dos setores e regióes, existe baixa relação entre as mudanças na estrutura produtiva e o crescimento da produtividade, destacando-se a componente regional residual. Os resultados confirmam que foram as vantagens competitivas inerentes a cada região que explicaram, em sua maioria, o crescimento da produtividade do trabalho nas regióes. Pode-se inferir que, nos anos analisados, as disparidades regionais e setoriais foram acentuadas, tendo em vista que não se identificou tendência à convergência no sentido de mudança na estrutura produtiva. Assim, nossa análise revelou que as diferenças na evolução da produtividade foram explicadas pela componente regional residual, que confere vantagens econômicas à maioria das regióes e dos setores. No entanto, tais vantagens competitivas locacionais foram importantes em nível regional, principalmente para as regióes menos desenvolvidas. Foram insuficientes, porém, para impulsionar o crescimento da produtividade do trabalho em nível nacional. 


\section{Referências bibliográficas}

ARCELUS, Francisco J. An extension of shift-share analysis. Growth and Change. USA, v. 1, n. 15, p. 3-8, 1984.

AZEVEDO, Paulo F. \& JÚNIOR, Rudinei T. Fatores determinantes da relocalização industrial no Brasil na década de 90. In: Anais do Encontro Nacional de Economia - ANPEC, 27, 1999, Belém. Belém: ANPEC, 1999.

BARFF, Richard A.; KNIGHT III, Prentio L. Dynamic shift and share analysis. Growth and Change. USA, v. 19, n. 2, p. 1-10, 1988.

BONELLI, R. Ganhos de produtividade na economia brasileira na década de 90 : um retrato de corpo inteiro. São Paulo: Especial SOBEET, III, 15. 2000.

BONELLI, Regis. Labor productivity in Brazil during the 1990s. Rio de Janeiro: IPEA, 2002 (Texto para Discussão, 906).

BONELLI, R.; FONSECA, R. Ganhos de produtividade e de eficiência: Novos resultados para a economia brasileira. Pesquisa e Planejamento Econômico,

Rio de Janeiro, v. 28, n. 2, p. 273-314, ago. 1998.
CANO, Wilson. Concentração e desconcentraçáo econômica no Brasil: 1970/95. Economia e sociedade, Campinas, v. 8 , p. 10141, jun. 1997.

CARVALHO JÚNIOR, Nelson Simão de; RUIZ, Ricardo Machado. Determinantes do desempenho das firmas a partir das novas capacitaçóes internas: Um estudo de firmas brasileiras. Revista de Economia Contemporânea, Rio de Janeiro, v. 12, n. 1, p. 97-127, jan./abr. 2008.

DE NEGRI, Fernanda; ALMEIDA, Mansueto (Org.). Estrutura produtiva avançada e regionalmente integrada:

Desafios do desenvolvimento produtivo brasileiro. Instituto de Pesquisa Econômica Aplicada. Brasília, livro 5, v. 1, IPEA, 2010.

DINIZ, Clélio C.

Desenvolvimento poligonal no Brasil: Nem desconcentraçáo, nem contínua polarização. Nova Economia. Belo Horizonte, v. 3, n. 1, p. 35-64, set. 1993.

DINIZ, Clélio C.; CROCCO,

Marco A. Reestruturação econômica e impacto regional: $\mathrm{O}$ novo mapa da indústria brasileira. Nova Economia. Belo Horizonte, v. 6, n. 1, jul. 1996.
DUNN, Edgar S. Jr. Une technique et analitique d' analyse régionale: Description et projection. Economie Appliquée. Paris, v. 12, n. 4, p. 521-530, act., 1959.

DUNN, Edgar S. Jr. A statistical and analitical technique for regional analysis. Papers and Proceedings of the Regional Science Association. USA, v. 6 , p. 97-112, 1960.

\section{ESTEBAN-MAQUILLAS J. M.}

Shift and share análisis revisited. Regional and Urban Economics.

North-Holland, v. 2, n. 3, p. 249-261, Oct. 1972.

FAGERBERG, Jan. Techonological progress, structural change and productivity grwth: A comparative study. Structural change and economics dynamics. Olso, p. 393-411, July 2000.

FEIJÓ, Carmem A.; CARVALHO, Paulo G. M. O debate sobre a produtividade industrial e as estatísticas oficiais. Economia Aplicada.v. 3, n. 4, out./dez. 1999.

FEIJÓ, Carmem A.; CARVALHO, Paulo G. Uma interpretação sobre a evoluçáo da produtividade industrial no Brasil nos anos noventa e as "leis" de Kaldor. Nova Economia, Belo Horizonte, v. 12 , n. 2 , p. $57-78,2002$.
FEIJÓ, Carmem A.; CARVALHO, Paulo G.; RODRIGUEZ,

Maristela S. Concentraçáo industrial e produtividade do trabalho na indústria de transformação nos anos 90 : Evidências empíricas. Economia, Niterói, v. 4, n. 1, p. 19-52, jan./ jun. 2003.

GALINDO, Osmil (Org.). Necessidades de infraestrutura econômica do Nordeste. In: Banco do Nordeste do Brasil. Diretrizes para um plano de ação do BNB (1991-1995); Infraestrutura econômica e social do Nordeste. v. 7, Fortaleza, 1997.

GUIMARÁES NETO, Leonardo. Desigualdades e políticas regionais no Brasil: Caminhos e descaminhos. Planejamento e politicas públicas. Brasília, IPEA, n. 15, jun. 1997.

GROSSMAN, G. M. \& HELPMAN, E. Comparative advantage and long-run growth. American Economic Review, v. 80, n. 4, p. $796-815,1990$

HAYNES, Kingsley E.; MACHUNDA, Zachary B. Considerations in extending shift-share analysis: Note. Growth and Change, USA, v. 18, n. 2, p. 69-72, 1987. 
HADDAD, Paulo Roberto; ANDRADE, Thompson A. Método de Análise Diferencial-Estrutural. In: HADDAD, Paulo Roberto; FERREIRA, Carlos Maurício de Carvalho; BOSIER, Sérgio; ANDRADE, Thompson A. (Org.). Economia regional: Teorias e métodos de análise. Fortaleza: BNB; ETENE, p. 249-286, 1989. (Estudos Econômicos e Sociais, 36).

IBGE. Instituto Brasileiro de Geografia e Estatística. Pesquisa Industrial Anual. Disponível em: $<$ http://www.ibge.gov.br/servidor_ arquivos_est/ $>$. Acesso entre: jun. a set. 2011.

IPEADATA. Instituto de Pesquisa Econômica e Aplicada. Índices de preços por atacado. Disponível em:<http://www.ipeadata.gov.br/ Default.aspx $>$. Acessos entre: jun. a set. 2011.

LAMONICA, Marcos T., FEIJÓ, Carmem A. Crescimento e industrialização no Brasil: Uma interpretação à luz das propostas de Kaldor. Revista de Economia Política, v. 31, p. 1-20, 2011.

LEMOS, M. B.; DINIZ, C. C., GUERRA, L. P., MORO, S. A nova configuração regional brasileira e sua geografia econômica. Estudos Econômicos, v. 33, n. 4, p. 665 700, 2003.

LODDER, Celsius Antônio.

Crescimento da ocupação regional e seus componentes. In: FERREIRA, Carlos Maurício C. et al. Planejamento regional: Métodos e aplicação ao caso brasileiro. Rio de Janeiro: IPEA; INPES, 1974. p. 53-110. (Série monográfica n. 8).
LYRA, Flávio T. Os incentivos fiscais à indústria da Zona Franca de Manaus: Uma avaliação (Relatório Final). Texto para Discussáo nr. 371. IPEA, Brasileira, maio 1995.

MONTEIRO NETO, Aristides. Intervenção estatal e desigualdades regionais no Brasil: Contribuiçóes ao debate contemporâneo. Texto para Discussão n. 1229, IPEA. Brasília, nov. 2006.

MOREIRA, Maurício Mesquita. A indústria brasileira nos anos 90. O que já se pode dizer? In: GIAMBIAGI, Fabio; MOREIRA, Maurício Mesquita (Orgs.). $A$ economia brasileira nos anos 90 . Rio de Janeiro: Banco Nacional de Desenvolvimento Econômico e Social, 1999.

NASSIF, André. Há evidências de desindustrialização no Brasil? Revista de Economia Politica, v. 28 n. 1, São Paulo, jan./mar. 2008.

OLIVEIRA, Carlos W. A.; MAGALHĀES, João C. R. (Org.). Estrutura produtiva avançada e regionalmente integrada: Diagnóstico e políticas de redução das desigualdades regionais. Instituto de Pesquisa Econômica Aplicada. Brasília, livro 5, v. 2, Ipea, 2010.

PACHECO, Carlos A.

Fragmentação da nação.

Campinas, SP:

UNICAMP/IE, 1998.
PACHECO, Carlos A. Novos padrōes de localização industrial? Tendências recentes dos indicadores da produção e do investimento industrial. Texto para discussão n. 633. IPEA, Brasília: 1999.

ROCHA, Frederico.

Produtividade do trabalho e mudança estrutural nas indústrias brasileiras extrativa e de transformação, 1970-2001. Revista de Economia Política. v. 27, n. 2, abr./jun. 2007.

ROMER, Paul M. Two strategies of economic development: using ideas and producing ideas. In: Proceedings of the 1992 World Bank Annual Conference on Economic Development. World Bank: Washington, DC., 1993a, p. 63-97.

\section{ROMER, Paul M. Idea Gaps} and object gaps in economic development. Journal of Monetary Economics, Rochester, 32, 1993b, p. 543-573.

RUIZ, Ricardo M.; DOMINGUES, Edson P. Aglomerações econômicas no Sul-Sudeste e no Nordeste brasileiro: Estruturas, escalas e diferenciais. Estud. Econ., v. 38, n. 4., out./dez. 2008.

SABÓIA, João. Desconcentração industrial no Brasil nos anos 90: Um enfoque regional. Pesq. Plan. Econ., Rio de Janeiro v. 30, n. 1, abr. 2000 .

STILWELL, F. J. B. Regional growth and structural adaption. Urban Studies. Glasgow, v. 8, n. 6, p. $162-78$, nov. 1969
STILWELL, F. J. B. Further thoughts on the shift and share approach. Departament of Economics, University of Sydney. Regional Studies, printed in Great Britain. v. 4, p. 451-458. Pergamon Press, 1970.

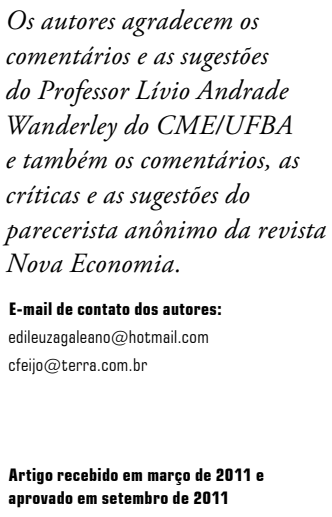


